\title{
The Cyclical Behavior of
}

\section{Short-term and Long-term Job Flows}

\author{
Andrew Figura* \\ Board of Governors of the Federal Reserve System \\ January 4, 2002
}

\begin{abstract}
Using a band pass filter, this paper estimates plant-level job flows at different frequencies and examines the characteristics of the high frequency (transitory) and low frequency (permanent) component flows. Because high frequency employment movements, which likely result in changes in the utilization of plant assets, and low frequency movements, which likely coincide with the restructuring of plant assets, result in different costs to the economy, understanding their separate behavior is important. High frequency plant-level employment fluctuations account for the majority of cyclical movements in aggregate manufacturing employment, but the temporal separation between job destruction and job creation is more pronounced for low frequency job flows, suggesting that permanent job flows reflect a more protracted employment adjustment process. To facilitate the evaluation of job flow models, many of which describe either transitory or permanent job flows, time series of job flows at different frequencies are presented in the appendix.
\end{abstract}

*Email: jfigura@frb.gov. Research for this paper was conducted at the Census Bureau's Center for Economic Studies and supported by a research fellowship from the Brookings Institution. The views in this paper are those of the author and not necessarily those of the U.S. Census Bureau, the Federal Reserve Board, or its staff. I would like to thank John Shea, Judy Hellerstein, John Chao, Plutarchos Sakellaris, Bruce Fallick, Darrell Cohen, Bill Wascher and Stephanie Aaronson. I would especially like to thank John Haltiwanger for supplying me with data, encouragement and much useful advice. 
Much of how one looks at aggregate employment and unemployment fluctuations is determined by whether micro-level (e.g. plant, worker) employment or unemployment flows are long-lasting or not. While there has been substantial research on short-term and long-term worker flows, as of yet there has been little work trying to distinguish short-term from long-term job flows. This is unfortunate because theoretically the two types of job flows are quite distinct, and models have been constructed to describe each type. But without data on the separate flows, it is difficult to evaluate the relevance of these models. This paper presents time series of shortterm and long-term job flows for the manufacturing sector, which should aid the evaluation of job flow models, while, at the same time, complementing previous studies on short-term and long-term worker flows. The different time series reveal that fluctuations in aggregate employment are driven predominantly by high frequency plant-level job flows (those with a period of between one and four years), but that the temporal separation of job flows is more pronounced for low frequency job flows (those with a period greater than 8 years). This suggests that high frequency plant-level job flows are more important for understanding cyclical fluctuations in employment, but that low frequency job flows have more lasting effects and reflect a more protracted adjustment process.

Studies on short-term and long-term worker flows have looked at flows into and out of employment and flows into and out of unemployment. Using data on temporary layoffs from a variety of sources, Feldstein (1975) emphasized the importance of temporary layoffs to fluctuations in aggregate employment in an attempt to focus policy measures on the adverse incentives of the Unemployment Insurance system. Examining CPS data on worker flows into and out of unemployment, Clark and Summers (1979) emphasized the importance of the longterm unemployed in an attempt to debunk claims that unemployment was primarily frictional and not unduly costly. Murphy and Topel (1987) also used CPS data to point to the importance of long-term unemployment in accounting for the rise in unemployment from the early 1970s to the late 1980s.

In contrast to the large empirical literature on permanent and temporary worker flows, empirical work on permanent and temporary job flows has been scant. Permanent and temporary job flows are distinct from permanent and temporary worker flows because permanent worker separations do not imply permanent job loss. Instead, a plant may lay-off a 
worker in a downturn and fill the same job with a different worker in the ensuing recovery. The worker flow is permanent, but the job flow is not. The costs of permanent worker and permanent job flows are different. Lost capital caused by permanent worker flows is limited to plant specific human capital, while capital lost due to permanent job flows includes not just plant-specific human capital, but also plant specific physical (Ramey and Shapiro, 1998) and organizational capital (Prescott and Visscher, 1980, and Atkeson and Kehoe, 2002).

Work on distinguishing between permanent and temporary job flows has been largely theoretical. Initially, such research emphasized long-term job flows related to the movement of resources from less productive to more productive job sites (Caballero and Hammour, 1994, 1996, and Mortensen and Pissarides, 1994). In examining the process of reallocating resources across job sites, these models highlighted job search and the sunk investment necessary to create new jobs. More recent descriptions of job flows have concentrated on short-term within-plant job flows (Ramey and Watson, 1997). These models look at the incentives and costs for plants to destroy and then recreate the same job. The costs of long-term reallocation-related and shortterm within-plant job flows are different. Leaving aside questions of efficiency, the difference resides in the fixed capital of a job that remains at the plant, when the job is vacated by a worker. This includes physical capital such as equipment and structures, as well as organizational capital, such as the accumulated knowledge of how to structure the production process most efficiently. The plant specific portion of this fixed capital will be destroyed if the job is permanently destroyed, and will have to be created anew in any job permanently created. This destruction and creation does not occur if a job is temporarily destroyed and then recreated.

In the absence of data on short-term and long-term job flows, researchers have relied on total job flows for both the motivation and evaluation of models of permanent and temporary job flows. For example, using a model of permanent job flows, Caballero and Hammour (1996) show that a low ratio of the variance of job creation to the variance of job destruction implies the existence of large sunk costs of job creation and the inability of employers to make binding wage contracts with workers prior to making these sunk investments. According to the model, this leads to inefficiencies as relocating workers must endure longer periods of unemployment moving from a low to a high productivity job. Though Caballero and Hammour use data on total job flows to motivate their model, to estimate, in the context of their model, the extent to which inefficiencies may plague the reallocation of jobs across production sites, one would want to use 
the behavior of long-term job flows. Ramey and Watson (1997) use a model of short-term job flows to illustrate how incentive problems may cause employment relationships to be severed inefficiently upon the arrival of a negative shock. This inefficient job destruction causes both the amplification and propagation of aggregate shocks. Because the model does not describe the long-term reallocation of jobs across plants, but a given set of plants destroying and then recreating jobs, one would want to use short-term job flows to evaluate predictions of the model and understand its implications. The time series of short-term and long-term job flows presented in this paper should be useful in better evaluating the empirical implications of job flow models, such as those mentioned above, and, also, it is hoped in motivating future research on short-term and long-term job flows.

In addition to the variance ratio, mentioned above, this paper looks at two other characteristics of job flows that have informed job flow models: the relationship between trend growth and the variance ratio (Foote, 1998) and the dynamic correlations of job flows (Caballero and Hammour, 1996, and Cole and Rogerson, 1999). For all three characteristics there are important differences between short-term and long-term job flow measures, and between both short-term and long-term job flows and total job flows. These differences reveal that it is misleading to use characteristics of total job flows when motivating, evaluating, or drawing implications from models of short-term or long-term job flows.

Because adjustment costs or other determinants of the behavior of short-term and longterm job flows may vary across plants with different sizes, productivity, etc., I also examine differences in both short-term and long-term job flows across various plant characteristics. The characteristics I examine are determined by the data, which contain information on wages, size, energy use, and labor productivity.

I find that high frequency plant-level job flows account for the majority of aggregate employment fluctuations, but that low frequency job flows are more temporally separated, that is increases in low frequency job creation do not soon follow increases in low frequency job destruction. Job flows with a period of between one and four years account for 56 percent of the cyclical change in aggregate employment, at least three times the share accounted for by job flows with a period of 5 to 8 years or job flows with a period greater than 8 years. While both job creation and job destruction are negatively correlated at high and low frequencies, dynamic autocorrelations show that permanent job flows are more temporally separated, or decoupled, 
than transitory job flows- the peak correlation between low frequency job creation and low frequency job destruction occurs when job destruction is lagged by over three years versus less than a year for high frequency job flows. Together these facts suggest that shorter-term job flows are particularly important for cyclical changes in employment, but that the costs and duration of employment adjustment may be larger for longer-term job flows.

Davis and Haltiwanger $(1990,1992)$ have found that a variance asymmetry (i.e.- job destruction has a greater variance than job creation) exists for total job flows. I find that the ratio of the standard deviation of job creation to the standard deviation of destruction is less than one for job flows at most frequencies, but the variance ratio for total job flows masks differences between the ratios for short-term and long-term job flows. The presence of a variance ratio less than one, 0.74 , for short-term (1-8 year) job flows suggests that an asymmetry in the cost of increasing versus decreasing plant-level employment may be important in the manufacturing sector, though because the variance ratio is closer to 1 for short-term job flows than for total job flows, these microeconomic asymmetries are perhaps smaller than thought previously. The variance ratio for long-term job flows is 0.43 , much smaller than the ratio for total job flows, 0.6. But once one controls for trend employment growth, this ratio becomes 0.91. Because the variance asymmetry in long-term job flows largely disappears after controlling for trend growth, factors which can explain the variance asymmetry in the absence of trend growth, such as labor market matching, Mortensen and Pissarides (1994) and sunk and convex costs of job creation, Caballero and Hammour (1996), must have a much smaller affect on the ratio than was once thought. ${ }^{1}$ It also suggests that modeling the relationship between trend growth and the variance ratio would be an important step toward understanding the reallocation process. Recognizing that the characteristics of job flows I have examined in the paper do not fully describe the data, I have included in the appendix time series of job flows at different frequencies. As many models of job flows implicitly describe either short-term or long-term job flows, these series should enable a more informative evaluation of job flow models.

The structure of this paper is as follows. Section 1 discusses the data and the method, the Baxter and King (1999) band pass filter, used to decompose job flows into short-term and longterm components. Section 2 describes the basic distinction between short-term and long-term

\footnotetext{
${ }^{1}$ Foote (1998) makes the same point examining total job flows.
} 
job flows and how this distinction can be empirically implemented with a band pass filter. Section 3 then looks at whether characteristics of total job flows as described by important stylized facts are present in the various components, and what this implies about some current models of job flows. Section 4 investigates how characteristics of plants (size, productivity, energy intensity, and wages) influence the behavior of the various components, and how this might inform models of job flows. Section 5 offers some conclusions. Time series of short-term and long-term job flows are presented in an appendix.

\section{Short-term and Long-term Job Flows}

\subsection{Data}

The data on plant-level job flows comes from the Census Bureau's Longitudinal Record Data set (LRD), which, in turn, derives from data from the Census of Manufacturers (CM) and the Annual Survey of Manufacturers (ASM). ${ }^{2}$ The CM collects data for the universe of manufacturing plants every 5 years, while the ASM, which is a rotating panel, collects data from approximately 50,000-70,000 plants for 5 consecutive years. The panel nature of the ASM allows the LRD to link plants across time within a 5 year panel. Around one-third of all plants can be linked across consecutive panels.

Job flows are defined as in Davis, Haltiwanger, and Schuh (1996), henceforth DHS. Aggregate job creation at time $t$ is the sum of employment changes across all plants with positive employment changes from $t-1$ to $t$. Aggregate job destruction is the sum of the absolute value of employment changes across all plants with negative employment changes from $t-1$ to $t$. To convert flows into rates, I divide by the average of employment in periods $t$ and $t-1$. The difference between job creation and job destruction at time $t$ is $\mathrm{NET}_{\mathrm{t}}$, and the sum of job creation and job destruction at time $t$ is $\mathrm{SUM}_{\mathrm{t}}$. For more information on the LRD and the construction of job flows, see DHS.

\footnotetext{
${ }^{2}$ Though the ASM is an annual survey, it asks firms to report employment for plants for four different months during the year.
} 


\subsection{Decomposition Method- Band Pass Filter}

To decompose employment changes into short-term and long-term components, I use a band pass filter from Baxter and King (1999). ${ }^{3}$ The band pass filter is applied as a symmetric moving average filter, whose weights are derived from the frequency domain representation of a time series. The filter specifies upper and lower cut-off frequencies and filters out fluctuations in a given series of a frequency greater than the upper cut-off and lower than the lower cut-off. Or, thinking it terms of periods rather than frequencies, the filter removes fluctuations with a period greater than a certain cut-off level and fluctuations with a period lower than a specified cut-off level. For example, if the cut-off periods are $c^{1}$ and $c^{2}$, with $c^{1}<c^{2}$, then changes in employment that occur within a period less than $\mathrm{c}^{1}$ are filtered out as are changes in employment that last for longer than $\mathrm{c}^{2}$ periods.

The spectral representation theorem allows one to represent any stationary time series by the sum of an infinite number of orthogonal series of different frequencies (see Priestly, 1981).

$$
y_{t}=\int_{-\pi}^{\pi} \xi(\omega) d \omega
$$

After applying an unspecified linear filter to a series, its spectral representation is

$$
y_{t}^{*}=a(L) y_{t}=\int_{-\pi}^{\pi} \alpha(\omega) \xi(\omega) d \omega
$$

where $\alpha(\omega)=\sum_{h=-K}^{K} a_{h} e^{i \omega h}$, and is the frequency response function of the linear filter $a(L)=\sum_{h=-K}^{K} a_{h} L^{h}$, where $\mathrm{L}$ is the lag operator. Thus, the series $\mathrm{y}_{\mathrm{t}}^{*}$ is a weighted sum of an infinite

\footnotetext{
${ }^{3}$ Christiano and Fitzgerald (1999) develop an alternative band pass filter, which uses all of the data in a time series, instead of a fixed window of forward and lagged values, but is asymmetric and non-stationary. Because asymmetric filters induce phase shift, which could distort correlations between filtered series, I use the Baxter King filter. In addition, as is discussed in sub-section 2.2 below, for most plants in my sample the data available beyond a 3 year forward and backward window is quite limited, reducing the advantage of the Christiano and Fitzgerald filter.
} 
number of cyclical series of different frequencies. The object of a low pass filter is to place a zero weight on frequencies above a specified cut-off point. Thus, if one wanted to filter out those components of a quarterly series with a period less than 3 years (12 quarters), then all $\alpha(\omega)$ such that $\omega>\frac{\pi}{6}$ should be set to $0 .{ }^{4}$

Once the appropriate frequencies are zeroed out, the revised series can be translated back into the time domain by recovering the coefficients of the linear filter as identified by the zeroing-out restrictions in the frequency domain.

$$
\begin{aligned}
& y_{t}^{f}=b(L) y_{t} \\
& b(L)=\sum_{h=-K}^{K} b_{h} L^{h} \\
& b_{h}=\frac{1}{2 \pi} \int_{-\pi}^{\pi} \beta(\omega) e^{i \omega h} d \omega \\
& \beta(\omega)=1 \text { if }|\omega| \leq \underline{\omega} \\
& \beta(\omega)=0 \text { if }|\omega|>\underline{\omega}
\end{aligned}
$$

where $\underline{\omega}$ is the cut-off frequency, and $\mathrm{y}^{\mathrm{f}}$ is the filtered series after removing fluctuations in the time series with frequencies greater than the cut-off frequency. The moving average coefficients, $b_{h}$, used to filter out high frequency components are derived from the frequency domain as the inverse Fourier transform of the frequency response function. Baxter and King (1999) show that band pass filters (filters that extract an interval of frequencies, e.g. greater than 4 quarters, but less than 20 quarters) can be derived from a linear combination of low pass filters.

The ideal linear filter would be a two way infinite lead/lag polynomial. While the data do not allow the application of such a filter, an accurate decomposition requires leads/lags of sufficient length. At the same time, the longer the filter the fewer the observations contained in the component series. Thus, there is a tension between desiring an accurate decomposition, on the one hand, and as many data points as possible, on the other. Baxter and King (1999) use simulations to examine this trade-off and recommend using 12 quarters of data backwards and

${ }^{4}$ If $\omega>\frac{\pi}{6}$, then the period, which equals $\frac{2 \pi}{\omega}$, is less than 12 . 
forwards to construct a band pass filter for business cycle frequencies. 5,6

\section{Short-term and Long-term Job Flows}

\subsection{Distinguishing Short-term from Long-term Job Flows}

There exists several models of short-term and long-term job flows. Long-term job flows are associated with models of restructuring or reallocation (Mortensen and Pissarides, 1994, and Caballero and Hammour, 1994, 1996). These models have several features in common. First, plant-level differences in the timing of either technology adoption or plant-level technology shocks create a distribution of job sites with different productivities. Second, there are costs, in the form of sunk investments in physical capital or job search, to creating new job sites and moving resources across job sites. If there were no costs and if there were a limitless supply of job sites with the latest or most efficient technology, then the movement of resources across job sites would result in a degenerate distribution of manned plants across productivity levels- i.e. all plants would operate with the most efficient technology and have identical productivity. Eventually, workers do move from less productive to more productive job sites, but only after the relative technologies of their job sites pass below some threshold level. Third, these costs also make the movement of workers from less productive to more productive job sites correlated with the cycle even though the arrival of new technologies or shocks to plant level technologies are not. In Mortensen and Pissarides (1994) for example, the opportunity cost of reallocation is the output foregone when workers search for new jobs instead of work. Since the value of this output is pro-cyclical, reallocation is counter-cyclical, despite the fact that shocks to plant-level technologies are not. Finally, changes to a plant's relative technology are permanent or are not expected to reverse themselves. Because the productivity of a plant is determined by the

\footnotetext{
${ }^{5}$ Baxter and King (1999) show that the optimal filter (the one that deviates in a mean squared sense the least from the ideal or infinite moving average filter) is formed by just truncating the infinite moving average filter. Baxter and King also impose the restriction that the frequency response function corresponding to the optimal filter has a value of 1 at frequency 0 for low pass filters.

${ }^{6}$ The band pass filter has both advantages and disadvantages. Because the decompositions are based on moving averages, they are easy to apply, an attractive attribute when decomposing employment for 20,000 plants. But the filter also smooths the long-term component, spreading out relatively long-lasting changes in employment over several periods. If one believes that permanent changes are one-time discrete events, then this feature of the filter can be problematic. The Baxter/King filter also depends on having a relatively long continuous time series of employment for a plant. Large plants are more likely to possess long time series, so that the resulting aggregate short-term and long-term job flows are not necessarily representative of the manufacturing sector. Unfortunately, all decomposition methods possess this feature to some extent, and it must be looked upon as a price one must pay in order to estimate decomposed job flows. Also, evidence from Figura (2001) indicates that the cyclical behavior of short-term and long-term job flows in large and small plants is not very different.
} 
characteristics (the organizational and physical capital) of the job site, which are permanent, once a job is destroyed, it is never recreated. And once a new job is created, it will endure for a long-time. It is this attribute of job flows related to reallocation that allows them to be identified with long-term job flows.

In short-term job flow models, shocks to plant-level productivity are temporary and do not cause lasting changes in employment. The production process at a plant is built to handle some normal or permanent level of demand for its product. But this does not mean that demand and output are constant at this level; instead, due to fluctuations in aggregate demand, seasonal variations or temporary idiosyncratic movements in demand, output and demand for labor fluctuate. But these movements are temporary so that the movements in job levels that they induce are high frequency, or short-term, movements. In Ramey and Watson (1997), for example, plants receiving adverse productivity shocks reduce employment. These adverse shocks arrive more frequently in downturns, but since the shocks are i.i.d., there is no tendency for them to persist and a plant that cuts jobs in period $t$ will very likely recreate those jobs at some point in the near future. Similarly, Campbell and Fisher (2000) model job flows at a fixed set of plants and include costs of employment adjustment- hiring and firing costs- that would apply to plants using short-term employment changes to accommodate temporary aggregate shocks to demand. ${ }^{7}$

\subsection{Measuring Short-term and Long-term Job Flows}

To construct aggregate long-term and short-term job flow series, I first create 16 overlapping 7 year panels from 1972-1993. The first panel, for example, covers the years 19721978, the second 1973-1979, etc. For each plant in each panel, I can use an 11 quarter forward and backward moving average filter to decompose employment changes for the middle year in the panel. ${ }^{8}$ With the first panel, for example, I can construct permanent and transitory job flows

\footnotetext{
${ }^{7}$ However, Campbell and Fisher (2000) model plant-level technology shocks as random walks, which should cause plant-level employment changes to persist. Thus, while the adjustment costs they specify seem likely to apply to short-term employment movements, the parameterization of plant-level technology shocks chosen by Campbell and Fisher (2000) likely causes long-term employment movements.

${ }^{8}$ I use an 11 quarter instead of a 12 quarter, the number recommended by Baxter and King, filter because the construction of job flows requires a difference operation on decomposed employment. Thus, a 12 quarter filter would not allow the construction of job flows for the first quarter of the middle year. The 11 quarter filter allows one to estimate employment decompositions for the 6 middle quarters of each panel. This means that each panel has permanent job flows for all of the quarters of its middle year as well as the first quarter of the next panel's middle year. To smooth the aggregate series, I take the average of the first quarter estimate from consecutive panels.
} 
for each plant for the four quarters of 1975. Plants in the overlapping panels account for $30-45 \%$ of the plants in the typical ASM panel and represent about two thirds of ASM employment and about half of total manufacturing employment.

The overlapping panels yield a time series of total job flows for 1975-1990 taken from the middle year of each panel. Table 1 compares the properties of this time series with the properties of time series of job flows for the entire ASM reported by DHS. For the most part the cyclical behavior of job flows is quite similar. The variance asymmetry is less pronounced for the overlapping panels, and this results from a slightly lower variance of job destruction. Correlations between the different measures of NET and Job Destruction across the different samples are both around .95 , while they are around .8 for Job Creation and SUM.

To implement the band pass filter, one must choose a cut-off date that separates fluctuations of employment associated with temporary demand shocks from longer-term fluctuations associated with shifts in tastes and technologies. I follow much of the literature, which appeals to Burns and Mitchell (1946) and uses an 8 year cut-off to separate fluctuations of business cycle duration from longer lasting changes. However, much of the activity in aggregate job flows is concentrated around an even shorter period encompassing recessions and their immediate recoveries, which appears to last about 4 years. ${ }^{9}$ To assess the importance of these recession/recovery flows, I split the short-term or cyclical component into two parts, a high frequency cyclical, to capture the recession/recovery effect, and a medium frequency cyclical, to capture fluctuations which last longer than the recession/recovery period but are still cyclical in duration. Thus, I specify three cut-off points- one to distinguish seasonal from short-term cyclical (1 year), one to distinguish high frequency cyclical from medium frequency cyclical (4 years), and one to distinguish cyclical from long-term (8 years) fluctuations. Most of the analysis below considers job flows from continuing plants, but births and deaths likely represent permanent job flows related to reallocation and restructuring, and I sometimes examine their behavior separately or along with permanent job flows.

\footnotetext{
${ }^{9}$ In support of the notion that recoveries are different from other phases of the cycle, Sichel (1993) finds that the behavior of GDP growth in recoveries is different from later phases of an expansion.
} 
Figure 1 graphs time series of each component flow, and table 2 exhibits basic statistics for the different components. ${ }^{10}$ In terms of magnitude, the most important job flows are those with a period of 1-4 years. As shown in table 2, average job flow rates of high frequency job flows are over 3 times the average rates of 5-8 year job flows or long-term job flows. ${ }^{11}$ While all types of job flows vary significantly over the cycle, because 1-4 year job flows are largest in magnitude, they also vary the most in absolute terms over the cycle (compare panel $\mathrm{C}$ with panels $\mathrm{A}$ and $\mathrm{D}$ and note the difference in scale). Rates of 1-4 year job destruction, for instance, average 1.23 percentage points more in recessions than in expansions, about 4 times the percentage point variation of 5-8 year and long-term job destruction. Thus, in accounting for the cyclical variation in aggregate employment, 1-4 year job flows appear to dominate. Still, each of the other two flows, 5-8 year and long-term, account for around 25 percent of overall job flows. Their magnitude and variance over the cycle make them important to any understanding of the cyclical behavior of employment and job flows.

\section{Characteristics of Short-term and Long-term Job Flows}

\subsection{Reviewing the Stylized Facts.}

Three characteristics of the cyclical behavior of total job flows have been emphasized in the literature: the variance ratio (the variance of job creation divided by the variance of job destruction) is less than 1 , the variance ratio is positively correlated with an industry's trend growth rate, and job flows are decoupled, or temporally separated. The first stylized fact is evident in the time series of total job creation and job destruction from the overlapping panels, figure 2, where recessions produce large spikes in job destruction followed in recoveries by more modest, but more persistent, increases in job creation. From panel E of table 1, the standard deviation of job destruction in the overlapping panels time series is $50 \%$ larger than the standard deviation of job creation.

\footnotetext{
${ }^{10}$ Because short-term job creation can occur at the same time as long-term job destruction, and visa versa, the sum of the component flows can be greater than measures of total job creation or job destruction.

${ }^{11}$ If births and deaths are included in long-term job flows, then high frequency job flows would be about twice as large as long-term job flows.
} 
Figure 3 shows a plot of the relationship between the standard deviation ratio and the trend growth rate of 4 digit manufacturing industries using job flows from the complete ASM. ${ }^{12}$ The $\mathrm{y}$ axis is the $\log$ of the standard deviation of job creation minus the log of the standard deviation of job destruction. The $\mathrm{x}$ axis is the $\log$ of mean job creation minus the $\log$ of mean job destruction. ${ }^{13}$ The graph shows a scatter plot of observations and a line representing the fitted values from a regression of the $\mathrm{y}$ axis variable on the $\mathrm{x}$ axis variable. The $\mathrm{t}$ statistic from the regression is highly significant and the graph shows a clear positive relationship between the two variables. The greater the trend growth rate, the greater the variance of job creation relative to the variance of job destruction.

To assess the temporal separation or decoupling of job flows, figure 4 presents dynamic correlations of job creation and job destruction from the overlapping panels. The contemporaneous correlation between job creation and job destruction, emphasized by Cole and Rogerson (1999), is negative. Looking at other correlations, one sees that the highest correlation, .36, occurs between job destruction at time $t-4$ and job creation at time $t$. Finally, figure 2 shows that job creation and job destruction are decoupled because they occur at different phases of the cycle- job creation in expansions and job destruction in recessions.

Many models have been proposed to explain these stylized facts. Some, such as Mortensen and Pissarides (1994), and Caballero and Hammour (1994, 1996), have emphasized permanent job flows and long-term reallocation, and others, such as Ramey and Watson (1997), have concentrated instead on short-term job flows and the costs of a plant destroying and later re-creating the same job. All have motivated and evaluated their models using characteristics of total job flows. It would be more appropriate, however, to use data on short-term job flows to motivate or evaluate models of short-term job flows and data on long-term job flows to motivate or evaluate models of long-term job flows. The next sub-sections look at measures of the variance asymmetry and decoupling for both short-term and long-term job flows.

\subsection{Variance Asymmetry}

The asymmetry in job flow variances shows the degree to which the job creation and job destruction margins are used to adjust employment to aggregate shocks (Caballero and

\footnotetext{
${ }^{12}$ Job flows were taken from John Haltiwanger's website: http://www.bsos.umd.edu/econ/haltiwanger/download.htm.

${ }^{13}$ These are the variables Foote (1998) uses in his regression.
} 
Hammour, 1994). If it is more costly for plants to create jobs than to destroy them, then job destruction may respond more to aggregate shocks than job creation. The relative responsiveness of the two flows has implications for the costs of downturns, the efficiency of reallocation, and how aggregate shocks are propagated across time (Caballero and Hammour, 1996, 1998). For example, in regard to long-term job flows, if there are convex costs of creating new jobs, then Caballero and Hammour (1996) show that job creation will be smoothed over time. In an efficient economy job destruction will also be smoothed so that job destruction does not get too far ahead of job creation and cause the economy to waste labor in unemployment. But if there exists sunk costs of job creation, and firms are not able to make binding wage contracts with workers before committing resources to job creation, then the response of job destruction to aggregate shocks is instead amplified, and it becomes more volatile, leading to a difference in variances (job destruction is more variable than job creation) that has implications for the efficiency of the economy's reallocation process. Although no short-term job flow model has been motivated by the variance asymmetry, Campbell and Fisher (2000) show that linear costs of employment adjustment, which may be applicable to short-term job flows, cause firms to adjust job destruction schedules more than job creation schedules in response to an aggregate shock, imparting a greater variance to job destruction. In this case, the variance asymmetry contains information about the degree of fixed costs of employment adjustment, such as hiring and firing costs. Thus, according to the above models of job flows, the variance asymmetry for long-term job flows provides information about the efficiency of reallocation, while the variance asymmetry for short-term job flows may contain evidence about the size of hiring and firing costs.

Table 2 presents job flow variances and ratios separately for high, medium, and low frequency job flows. For both high and low frequency job flows, the variance of job creation is smaller than the variance of job destruction, but the asymmetry is larger for low frequency job flows, 0.43 , versus 0.87 for high frequency flows. For medium frequency job flows (5-8 years) the variance of job creation is slightly larger than the variance of job destruction. The asymmetry for 1-4 job flows may be exacerbated by the large job destruction observation in 
1975:1 and the fact that data constraints do not allow the increase in job destruction in the 199091 recession to be followed by an increase in job creation soon afterwards. ${ }^{14}$

The asymmetry for job flows with periods between 1 and 8 years (total cyclical job flows), at 0.74 , is more pronounced than that of either high frequency or medium frequency job flows, which suggests a greater correlation of high and medium frequency cyclical job destruction than of high and medium frequency cyclical job creation. The actual correlations are 0.43 for job destruction and 0.04 for job creation. Apparently, high and medium frequency job destruction are relatively tightly concentrated in recessions, while high and medium frequency job creation are more dispersed throughout an expansion, with high frequency job creation concentrated in the early stages of a recovery and medium frequency job creation occurring further on in an expansion. Thus, the asymmetry for total cyclical, or short-term, job flows occurs because increases in job creation following a recession can be quite drawn out.

In summary, the variance asymmetry is especially pronounced for long-term job flows, ${ }^{15}$ and the variance asymmetry for 1-8 year job flows reflects a tendency for high and medium frequency job creation to occur at different stages of an expansion. To investigate the issue further, I turn to the next sylized fact- the positive relationship between trend growth rates and the variance asymmetry.

\subsection{Trend Growth and the Variance Asymmetry}

Foote (1998) ran the following regression for 4 digit manufacturing industries

$$
\log \left(\frac{\operatorname{std}\left(j c_{i}\right)}{\operatorname{std}\left(j d_{i}\right)}\right)=\alpha+\beta^{*} \log \left(\frac{\operatorname{mean}\left(j c_{i}\right)}{\operatorname{mean}\left(j d_{i}\right)}\right)
$$

where $j c$ is job creation, $j d$ is job destruction, and $i$ indexes industry. In the same spirit, I separate plants into percentiles of net growth (where net growth is defined as average employment in year 7 of the panel minus average employment in year 1 of the panel, divided by average employment over the entire 7 year panel) and regress the log of the standard deviation

\footnotetext{
${ }^{14}$ If one attempts to control for these factors by limiting the sample period to 1977 to 1989 , the standard deviation ratio for 1-4 year job flows is 0.95 .

${ }^{15}$ Including births and deaths with long-term job flows lowers the asymmetry because the variance ratio of births and deaths is significantly greater, at 0.85 , than the variance ratio for long-term job flows of continuing plants. Still, even including births and deaths, the long-term variance ratio is 1.5 .
} 
ratio for job flows in a percentile against the $\log$ of the mean ratio for the percentile. ${ }^{16}$ To measure the responsiveness of the standard deviation ratio to changes in net employment growth, table 3 shows the magnitudes of the $\beta$ coefficients and the $\mathrm{R}^{2} \mathrm{~s}$ for the various component flows. ${ }^{17}$ $\beta$ coefficients are large and significant for long-term job flows. $\mathrm{R}^{2} \mathrm{~s}$ are also very high, .99 , for long-term job flows, but negligible for high frequency job flows, as is apparent from figure 5, which shows scatter plots of standard deviation ratios against percentiles of net growth for job flows at different frequencies. Trend growth has essentially no affect on the variance ratio of 1-8 year job flows, but very large effects on job flows with a period greater than 8 years.

After trend growth is controlled for, the variance ratio for long-term job flows appears close to 1 . According to the regression results, if trend growth is 0 , then the variance asymmetry for long-term job flows should be 0.91 , compared to 0.74 for 1-8 year job flows.

In explaining the relationship between trend growth and the variance asymmetry, Foote (1998) uses a model with fixed costs of employment adjustment. Fixed costs cause plants to adjust employment levels infrequently and to make large discrete changes when they do adjust. If there were no adjustment costs, plants would adjust employment in response to each shock it receives as it receives it. But with fixed costs of adjustment, plants will wait until the benefits from adjusting outweigh the costs. Foote shows that in industries with negative trend growth rates, many jobs are bunched along the downward adjustment threshold, waiting to be destroyed, and relatively few along the job creation margin. Consequently, there is a larger change in aggregate job destruction when a negative aggregate shock occurs and pushes plants over the job destruction threshold, than there is of job creation when a positive shock occurs. Given symmetry in aggregate shocks, this causes the variance of job destruction to exceed the variance of job creation. The reverse pattern occurs in trend growth industries.

Whether mechanisms, such as labor market matching (Mortensen and Pissarides, 1994) and sunk and convex costs of job creation (Caballero and Hammour, 1994, 1996) can also

\footnotetext{
${ }^{16}$ Computing standard deviation ratios by percentiles of net growth rather than by industry should offer a clearer read of the relationship. Standard deviations and means are computed for the whole sample, 1975-1990, after linking job flows for each percentile across panels, i.e. job flows for the ith percentile from the 1972-78 panel are linked to job flows for the ith percentile in the 1973-1979 through 1987-1993 panels, for $i=1$ to 100.

${ }^{17}$ The regression for long-term job flows does not include births and deaths.
} 
explain the relationship between the variance ratio and trend growth is unclear. These models can explain the existence of a ratio less than 1 when trend growth is 0 . But the variance ratio for long-term job flows of continuing plants after controlling for trend growth is close to 1 , and the variance ratio for births and deaths after controlling for trend growth is actually greater than $1 .^{18}$ Thus, the relevance of these models is hard to assess. More research about what aspects of these models may enable them to match the variance ratio/trend growth relationship and other features of long-term job flows would be useful in this regard.

The variance asymmetry in short-term job flows, on the other hand, is quite different. Essentially all of the variance asymmetry of short-term job flows remains unexplained by trend growth rates. Microeconomic, or plant-level, asymmetries in adjustment costs, relevant to a plant temporarily destroying jobs more quickly in a downturn than it later creates them in a recovery, may be an explanation for the variance asymmetry in short-term job flows.

\subsection{Decoupling}

The decoupling of job creation and job destruction contributes to the persistence of employment and unemployment fluctuations, as increases in job destruction are followed only with some delay by increases in job creation. In short-term job flow models, this decoupling is explained by the persistence of the underlying shock and the option to substitute home production or leisure for labor. Thus, in response to a negative aggregate shock, workers at the least productive jobs or with the best outside options engage in home production or leisure, as the returns from these activities become relatively more favorable. ${ }^{19}$ When the shock disappears, these workers return to the workplace. Ramey and Watson (1997) is an example of this approach. Jobs are destroyed when an adverse shock causes productivity at a job site to pass below some threshold level. When the adverse shock is reversed the job site hires workers back again.

In models that stress reallocation as the primary determinant of job flows, the activity outside of work is job search. Negative aggregate shocks induce workers to leave lower productivity jobs to look for more productive ones. If search is time consuming, then job

\footnotetext{
${ }^{18}$ This is based on a regression similar to Foote's (1998) for births and deaths in 2 digit manufacturing industries.

${ }^{19}$ Of course, this substitution between labor and leisure/home production need not be efficient.
} 
creation can be decoupled from job destruction. Cole and Rogerson (1999) show that if one uses the average exit rate from unemployment, then finding new jobs is a relatively quick process, and the decoupling of total job flows cannot be explained by a Mortensen and Pissarides (1994) style model. If, however, one uses the exit rate from unemployment and those not in the labor force but would like a job, a lower exit rate results, and job search becomes quite time consuming. This parameterization of a Mortensen and Pissarides model can explain decoupling (or a negative contemporaneous correlation between job creation and job destruction) because a lower exit rate means that job creation does not respond much to changes in the stock of unemployed workers and reacts mostly to the vacancy rate instead. Caballero and Hammour (1996) provide an alternative explanation for the decoupling of long-term job flows, showing that sunk costs of job creation and the absence of complete contracting causes job creation to respond to increases in job destruction only with some delay. Before firms will commit to creating new jobs, unemployment must rise and put downward pressure on wages.

Thus, decoupling in long-term job flows likely reflects the costs and coordination difficulties in moving a worker permanently from one job site to another (Cole and Rogerson, 1999) or in destroying the specific capital of one job site and investing in the capital of a new one (Caballero and Hammour, 1996). Decoupling in short-term job flows, on the other hand, may instead reflect persistent shocks and the temporary substitution of home production or leisure for work. ${ }^{20}$ Figure 6 graphs dynamic autocorrelations between job creation and job destruction for four different job flow frequencies: 1-4 years, 5-8 years, 1-8 years, and more than 8 years. ${ }^{21}$ The contemporaneous correlation between creation and destruction is negative for both short-term and long-term job flows, but decreases in frequency and is extremely low for long-term job flows.

The contemporaneous correlation of short-term (1-8 year) job flows is -0.53 . Correlations are also negative between job creation at time $t$ and job destruction between times $t$ 1 and $t+3$. The evidence appears consistent with a persistent shock explanation of short-term job

\footnotetext{
${ }^{20}$ Short-term job flows could also describe the temporary reallocation of workers across sectors, from manufacturing to services in a recession and then back to manufacturing again in an expansion, see Barlevy (1998).

${ }^{21}$ Long-term job flows do not include births and deaths.
} 
flows, with adverse aggregate shocks lasting about a year and causing job destruction to rise and job creation to fall as workers move out of employment and into activities, such as leisure and home production.

The contemporaneous correlation of long-term job flows is -0.78. In addition, long-term job destruction from $t-8$ to $t+8$ is negatively correlated with long-term job creation at time $\mathrm{t}$, and long-term job destruction must lead long-term job creation by over 3 years before the peak correlation between creation and destruction results. Periods of high long-term job creation occur well after periods of high long-term job destruction. Thus, decoupling in long-term job flows is quite severe and casts some doubt on the Cole and Rogerson explanation for decoupling. The contemporaneous correlation of total job flows, $-0.45^{22}$, which Cole and Rogerson found the Mortensen and Pissarides model could match is considerably smaller in absolute terms than the contemporaneous correlation for long-term job flows, -0.78 , suggesting that the job finding rate would have to fall considerably further to produce as strong a negative correlation as found in long-term job flows. However, it could be that unemployment resulting from long-term job destruction is different from other unemployment, and that exit rates from it are much lower (Loungani and Rogerson, 1989, Starr-McLuer, 1993, and Darby, Haltiwanger and Plant, 1985). In this case, a Mortensen and Pissarides model may well be capable of matching the data. Alternatively, the decoupling could be due to sunk costs of job creation and imperfect contracting (Caballero and Hammour, 1996). But since Caballero and Hammour do not calibrate their model, it is uncertain what level of sunk costs is necessary to generate such severe decoupling.

For both decoupling and the variance asymmetry, there are differences between the 197479 recession/expansion and the 1980-1985 recession/expansion. In the earlier period, the variance asymmetry is present predominantly in short-term job flows, while in the latter period it is present predominantly in long-term job flows. This is consistent with the variance in longterm job flows being driven primarily by trend growth rates. In the 1970s, there was no trend growth in the manufacturing sector, while in the 1980s trend growth was negative. Also, while

\footnotetext{
${ }^{22}$ Cole and Rogerson (1999) detrend job flows before computing a contemporaneous correlation and report results for data going through 1988; thus, their contemporaneous correlation measure differs somewhat from the measure for total job flows shown in figure 4.
} 
during the 1970s, decoupling of long-term job flows was very pronounced, in the 1980s it was less so.

The above evidence shows that both short-term and long-term job flows possess important attributes of overall job flows but to differing degrees and likely for different reasons. To shed more light on what may be behind the decoupling and variance asymmetry of both short-term and long-term job flows, the next section looks at how these vary across different plant characteristics.

\section{What Influences the Behavior of Short-term and Long-term Job Flows?}

Foote (1998) uses the difference in variance asymmetries across industries of different trend employment growth rates to rethink the reasons behind the variance asymmetry in total job flows. In a similar spirit, I use differences in variance asymmery and decoupling for short-term and long-term job flows across size, average wages, energy intensity, and shipments per worker to try to understand what underlying causes may be at work. Tables 4 and 5 show the variance ratio and contemporaneous correlation of job creation and job destruction for size, energy intensity, average wages, and shipments per worker deciles for job flows at four frequencies: those with periods between $1-4,5-8,1-8$ years and greater than 8 years. ${ }^{23}$ The main result is that the patterns of variance asymmetries and decoupling found in the aggregate data are also present at more disaggregated levels and across a broad spectrum of plant characteristics. Rather than depending on a particular characteristic of a plant, the levels of variance ratios and decoupling found in section 3 seem to be quite similar across nearly all plant types.

Panels B, C and D of table 4 show that short-term job flows for plants with different energy intensity, level of wages, shipments per worker, and size all possess the features of the variance asymmetry present in aggregate short-term job flows. 1-4 year cyclical asymmetries

\footnotetext{
${ }^{23}$ Size is the average number of production workers over the 7 year panel. Energy intensity is the average cost of fuels plus the average cost of electricity as a fraction of the average total value of shipments. Wages are average production worker wages, and shipments per worker is average total value of shipments divided by the average number of production workers. Job flow standard deviations and contemporaneous correlations are computed for the full sample, 1975-1990 after linking job flows of a given decile across panels, i.e. high frequency job flows for the ith decile of wages in the 1972-78 panel are linked with high frequency job flows for the ith decile of wages in the 1973-79 through 1987-1993 panels.
} 
are greater than 5-8 year, and the 1-8 year asymmetry is greater still. Beyond this, no pattern stands out. Whatever causes the variance asymmetry in short-term job flows apparently causes the same degree of asymmetry in all plants, no matter their characteristics. Turning to long-term job flows, energy intensity and the level of wages appear to affect the variance asymmetry, but the underlying cause is likely trend growth. Panel A of table 4 shows that high energy intensive plants have low variance ratios, but these plants also exhibit long-term employment declines. The same is true for high wage plants. Thus, the dominant source of asymmetry in long-term job flows continues to be trend growth.

Panels B, C, and D of table 5, which display the contemporaneous correlation between job creation and job destruction, shows that only size appears to significantly affect decoupling for short-term job flows. Small plants exhibit relatively little decoupling. The reason for this is unclear, but may be related to large seasonal changes in job flows for small plants and the leakage of seasonal flows into measures of 1-4 year job flows. Using quarterly data for total job flows, the correlation between total job creation and total job destruction is slightly positive for small plants, but in annual data the correlation is around $-0.5 .^{24}$ For low frequency job flows, there does not appear to be a relationship between any of the four characteristics and decoupling. In Panel A of table 5 decoupling at all deciles is quite severe with all correlations less than -0.47 and most less than -0.75. Any explanation of the decoupling in long-term job flows must, therefore, not only account for its severity, but also for its pervasiveness.

\section{Conclusion}

Looking at flows of workers and jobs has helped economists understand movements in aggregate employment. Rather than just looking at changes in the level of employment, attention has focused instead on the separate flows into and out of employment. Another useful disaggregation in employment data concerns the distinction between short-term and long-term employment flows. Up to now attempts to distinguish short-term and long-term job flows have

\footnotetext{
${ }^{24}$ The data for this analysis were taken from John Haltiwanger's website: www.bsos.umd.edu/econ/haltiwanger/download.htm. For medium frequency job flows, the correlation between job creation and job destruction is, also, significantly negative.
} 
been fairly primitive, and I am unaware of any attempts to analyze the separate behavior of these different types of job flows. This paper has attempted to partially fill this void.

I find that high frequency job flows account for the majority of aggregate employment fluctuations, but that low frequency job flows are more temporally separated, suggesting a more drawn out adjustment process. In addition, measures of important characteristics of job flows differ between short-term and long-term job flows and between these component job flows and total job flows. The presence of a variance ratio less than 1 in short-term (1-8 year and 1-4 year) job flows is evidence for the existence of an asymmetry in the costs of increasing and decreasing plant-level employment. What causes these asymmetries is uncertain. But the causal factor appears to be omnipresent, affecting plants with a variety of different characteristics in a similar fashion. The extent of the asymmetry, however, is smaller than would be suggested by looking at total job flows. While trend growth has no influence on the variance asymmetry of short-term job flows, it is the dominant explanation for the variance asymmetry in long-term job flows. Controlling for trend growth reduces the estimated variance asymmetry in long-term job flows dramatically, making it similar to that of high frequency job flows. Though decoupling or the temporal separation of job flows, exists for job flows of all frequencies, it is particularly pronounced for long-term job flows. It is also ubiquitous in long-term job flows, as no observable attribute of plants appears to account for it. The extent of decoupling in long-term job flows, as measured by the contemporaneous correlation of long-term job creation and job destruction, would be difficult for standard matching models of reallocation, such as Mortensen and Pissarides (1994), to generate and suggests that heterogeneity in search behavior may be important.

Because the underlying determinants and consequences of short-term and long-term job flows are different, researchers constructing models of job flows should be explicit about the type of job flow present in their models and should compare the behavior of job flows in their models to the behavior of the relevant type of job flow rather than to the behavior of overall job flows. If a model of reallocation describes long-term job flows, then empirical analysis of the model should use the behavior of the long-term component of job flows, and similarly for 
models of short-term job flows. Time series of component job flows are presented in the appendix to facilitate this more precise type of empirical analysis.

As mentioned previously, short-term and long-term job flows do not necessarily correspond to short-term and long-term worker flows. An unresolved question is how much of short-term flows for plants are in fact permanent flows for workers. Given the length of the period for even high frequency job flows ( 1 to 4 years) one might expect a large share of them to be. Thus, even though high frequency job flows cause no reallocation of jobs across plants, they could cause considerable reallocation of workers across jobs. Whether this reallocation is efficient and how it effects the short-term and long-term earnings of workers are interesting questions for future research to try to answer. 


\title{
Appendix
}

\author{
Total >8 years 1-8 Years 1-4 Years 5-8 Years \\ Date JC JD JC JD JC JD JC JD JC JD \\ $\begin{array}{lllllllllll}75 \mathrm{Q} 1 & 2.13 & 10.80 & 0.61 & 0.77 & 1.48 & 7.57 & 1.58 & 6.38 & 0.37 & 1.67\end{array}$ \\ $\begin{array}{lllllllllll}75 \mathrm{Q} 2 & 4.31 & 7.31 & 0.62 & 0.85 & 2.41 & 6.08 & 2.54 & 5.04 & 0.45 & 1.61\end{array}$

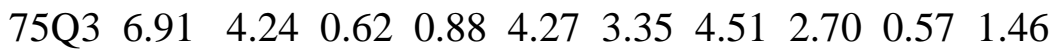

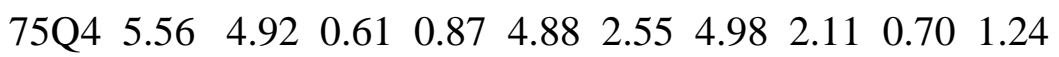 \\ 76Q1 $4.16 \quad 4.16 \quad 0.66 \quad 0.79 \begin{array}{lllllll}3.94 & 2.88 & 3.92 & 2.56 & 0.71 & 1.01\end{array}$ \\ $\begin{array}{lllllllllll}\text { 76Q2 } & 4.93 & 3.21 & 0.68 & 0.73 & 3.41 & 2.90 & 3.23 & 2.81 & 0.90 & 0.81\end{array}$

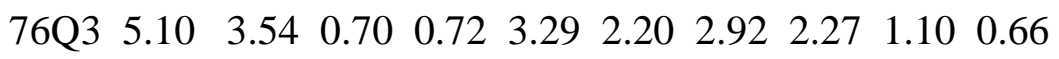 \\ $\begin{array}{lllllllllll}\text { 76Q4 } 4.77 & 4 \mathrm{Q} 4 & 0.68 & 0.70 & 3.48 & 2.44 & 2.80 & 2.58 & 1.39 & 0.57\end{array}$ \\ $\begin{array}{lllllllllll}77 \mathrm{Q} 1 & 3.91 & 3.97 & 0.77 & 0.63 & 3.05 & 2.95 & 2.46 & 3.16 & 1.32 & 0.52\end{array}$

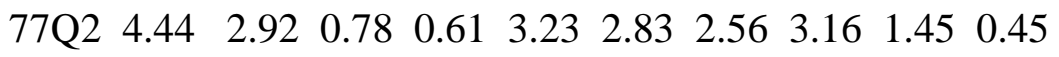

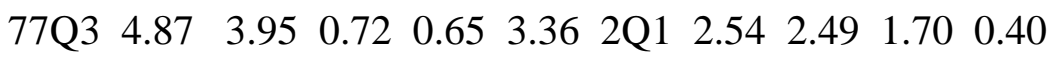 \\ $\begin{array}{lllllllllll}77 Q 4 & 5.16 & 4.12 & 0.71 & 0.65 & 3.23 & 2.32 & 2.44 & 2.71 & 1.62 & 0.44\end{array}$

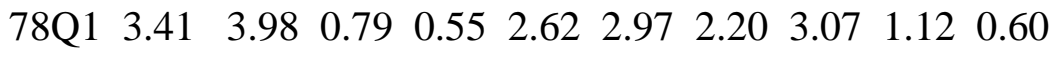

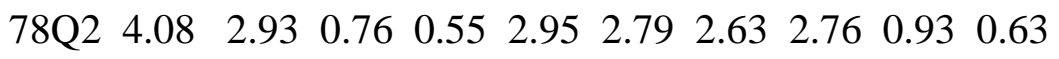 \\ $\begin{array}{lllllllllll}78 Q 3 & 4.48 & 4.01 & 0.71 & 0.62 & 3.24 & 1.87 & 2.99 & 1.82 & 0.90 & 0.69\end{array}$

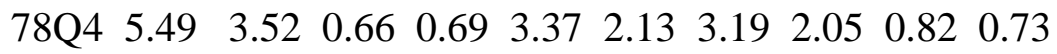

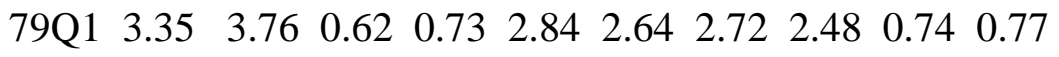 \\ $\begin{array}{lllllllllll}79 Q 2 & 3.37 & 2.93 & 0.56 & 0.82 & 2.76 & 2 \mathrm{Q} & 2.53 & 2.55 & 0.79 & 0.76\end{array}$

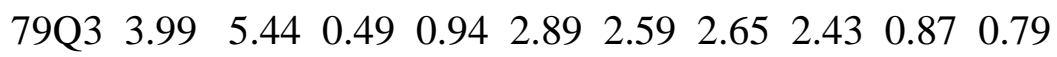 \\ 79Q4 $4.64 \quad 4.690 .45 \quad 1.052 .56 \quad 2.992 .33 \quad 2.78 \quad 0.86 \quad 0.83$ \\ $\begin{array}{lllllllllll}80 Q 1 & 2.98 & 5.02 & 0.42 & 1.14 & 2.22 & 4.10 & 1.99 & 3.85 & 0.78 & 0.81\end{array}$ \\ $\begin{array}{lllllllllll}80 Q 2 & 2.88 & 7.54 & 0.41 & 1.23 & 2.32 & 4.70 & 2.12 & 4.36 & 0.73 & 0.87\end{array}$ \\ $\begin{array}{lllllllllll}80 Q 3 & 4.48 & 6.12 & 0.40 & 1.35 & 2.62 & 3.46 & 2.59 & 3.10 & 0.70 & 1.02\end{array}$ \\ $\begin{array}{lllllllllll}80 \mathrm{Q} 4 & 6.53 & 3.81 & 0.39 & 1.40 & 3.88 & 2.54 & 4.08 & 2.23 & 0.60 & 1.11\end{array}$ \\ $\begin{array}{lllllllllll}81 \mathrm{Q} 1 & 3.36 & 4.93 & 0.39 & 1.35 & 4.56 & 2.57 & 4.94 & 2.19 & 0.46 & 1.22\end{array}$ \\ $\begin{array}{lllllllllll}81 \mathrm{Q} 2 & 4.08 & 3.43 & 0.40 & 1.31 & 3.52 & 2.65 & 3.93 & 2.17 & 0.43 & 1.33\end{array}$
}


Total >8 years 1-8 Years 1-4 Years 5-8 Years Date JC JD JC JD JC JD JC JD JC JD

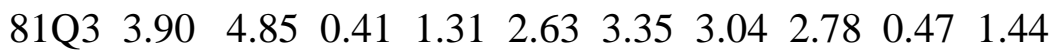
$\begin{array}{lllllllllll}81 Q 4 & 3.84 & 6.13 & 0.43 & 1.35 & 2.34 & 3.95 & 2.61 & 3.33 & 0.52 & 1.41\end{array}$ $\begin{array}{lllllllllll}82 \mathrm{Q} 1 & 2.88 & 7.24 & 0.48 & 1.34 & 2.42 & 4.60 & 2.51 & 3.89 & 0.55 & 1.35\end{array}$ $\begin{array}{lllllllllll}82 \mathrm{Q} 2 & 3.41 & 6.25 & 0.51 & 1.35 & 2.45 & 5.03 & 2.37 & 4.45 & 0.70 & 1.20\end{array}$

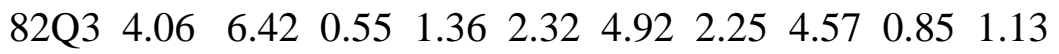
$\begin{array}{lllllllllll}82 \mathrm{Q} 4 & 3.62 & 7.25 & 0.58 & 1.38 & 2.69 & 4.17 & 2 \mathrm{Q} 3 & 4.03 & 1.03 & 0.98\end{array}$ $\begin{array}{lllllllllll}83 Q 1 & 5.02 & 4.95 & 0.63 & 1.31 & 3.73 & 3.35 & 3.40 & 3.26 & 1.08 & 0.84\end{array}$ $\begin{array}{lllllllllll}83 \mathrm{Q} 2 & 4.91 & 3.37 & 0.66 & 1.20 & 4.59 & 2.61 & 4.20 & 2.61 & 1.15 & 0 \mathrm{Q} 4\end{array}$ $\begin{array}{lllllllllll}83 Q 3 & 5.26 & 3.22 & 0.63 & 1.16 & 4.47 & 1.85 & 3.95 & 2 Q 1 & 1.31 & 0.63\end{array}$

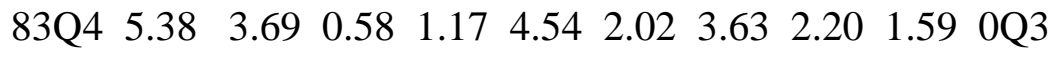
$\begin{array}{lllllllllll}84 Q 1 & 6.04 & 3.83 & 0.61 & 1.07 & 4 Q 4 & 2.47 & 3.84 & 2.58 & 1.48 & 0.45\end{array}$ $\begin{array}{lllllllllll}84 Q 2 & 4.40 & 2.72 & 0.60 & 1 Q & 4 Q 3 & 2.21 & 3.64 & 2.37 & 1.47 & 0.45\end{array}$

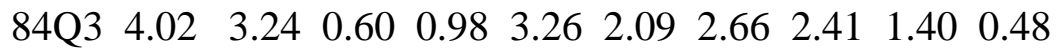
$\begin{array}{lllllllllll}84 \mathrm{Q} 4 & 3.55 & 4.33 & 0.61 & 0.95 & 2.42 & 3.24 & 2.01 & 3.47 & 1.22 & 0.58\end{array}$ $\begin{array}{lllllllllll}85 \mathrm{Q} 1 & 3.16 & 5.79 & 0.66 & 0.85 & 2.30 & 4.07 & 2.03 & 3.96 & 0.89 & 0.74\end{array}$ $\begin{array}{lllllllllll}85 \mathrm{Q} 2 & 3.24 & 3.77 & 0.67 & 0.80 & 2.64 & 3.46 & 2.51 & 3.16 & 0.74 & 0.90\end{array}$ $\begin{array}{lllllllllll}85 Q 3 & 3.73 & 4.11 & 0.68 & 0.80 & 2.61 & 2.61 & 2.74 & 2.31 & 0.67 & 1.11\end{array}$ $\begin{array}{lllllllllll}85 \mathrm{Q} 4 & 3.80 & 4.24 & 0.69 & 0.79 & 2.45 & 3.14 & 2.67 & 2.62 & 0.58 & 1.32\end{array}$ $\begin{array}{lllllllllll}86 Q 1 & 3.27 & 5.38 & 0.69 & 0.77 & 2.30 & 3.74 & 2.49 & 3.10 & 0.49 & 1.32\end{array}$ $\begin{array}{lllllllllll}86 \mathrm{Q} 2 & 2.90 & 3.63 & 0.67 & 0.79 & 2.55 & 3.59 & 2.63 & 3.01 & 0.56 & 1.21\end{array}$

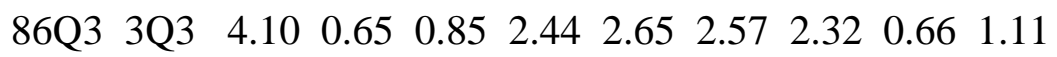

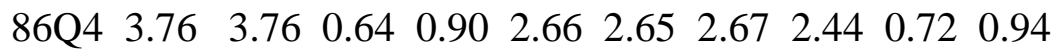
$\begin{array}{lllllllllll}87 Q 1 & 4 Q 1 & 4.42 & 0.66 & 0.89 & 2.99 & 3.07 & 2.74 & 2.85 & 0.81 & 0.78\end{array}$ $\begin{array}{lllllllllll}87 Q 2 & 3.51 & 3.30 & 0.66 & 0.88 & 3.25 & 2.72 & 2.82 & 2.65 & 1.01 & 0.65\end{array}$ $\begin{array}{lllllllllll}87 Q 3 & 4.35 & 3.32 & 0.65 & 0.89 & 3.03 & 1.98 & 2.63 & 2.09 & 1.12 & 0.61\end{array}$ $\begin{array}{lllllllllll}87 \mathrm{Q} 4 & 4.12 & 3.29 & 0.65 & 0.88 & 2.98 & 2.18 & 2.55 & 2.28 & 1.13 & 0.60\end{array}$ $\begin{array}{lllllllllll}88 \mathrm{Q} 1 & 3.71 & 4.11 & 0.66 & 0.83 & 3.04 & 2.66 & 2.59 & 2.67 & 1.04 & 0.58\end{array}$ 


\begin{abstract}
Total >8 years 1-8 Years 1-4 Years 5-8 Years
Date JC JD JC JD JC JD JC JD JC JD

$\begin{array}{lllllllllll}88 Q 2 & 3.46 & 3.12 & 0.63 & 0.84 & 3.08 & \text { 2Q3 } & 2.59 & 2.60 & 1.13 & 0.54\end{array}$

$\begin{array}{lllllllllll}88 Q 3 & 3.92 & 3.40 & 0.60 & 0.85 & 2.56 & 1.96 & 2.18 & 2.12 & 1.09 & 0.55\end{array}$

$\begin{array}{lllllllllll}88 Q 4 & 4.14 & 3.39 & 0.59 & 0.88 & 2.76 & 2.41 & 2.38 & 2.43 & 1.01 & 0.60\end{array}$

$\begin{array}{lllllllllll}89 Q 1 & 4.51 & 5.45 & 0.58 & 0.84 & 3.12 & 2.81 & 2.83 & 2.68 & 0.80 & 0.64\end{array}$

$\begin{array}{lllllllllll}89 Q 2 & 2.55 & 2.35 & 0.56 & 0.83 & 2.77 & 2.35 & 2.59 & 2.20 & 0.74 & 0.71\end{array}$

$\begin{array}{lllllllllll}89 Q 3 & 3.66 & 3.74 & 0.54 & 0.86 & 2.14 & 2.34 & 2.13 & 2.22 & 0.71 & 0.83\end{array}$

$\begin{array}{lllllllllll}89 Q 4 & 3.33 & 4.06 & 0.53 & 0.90 & 2.17 & 3.11 & 2.08 & 2.79 & 0.66 & 0.89\end{array}$

$\begin{array}{lllllllllll}90 Q 1 & 3.96 & 6.34 & 0.53 & 0.91 & 2.64 & 3.21 & 2.61 & 2.82 & 0.55 & 0.91\end{array}$

$\begin{array}{lllllllllll}90 Q 2 & 2.71 & 2.24 & 0.51 & 0.92 & 2.80 & 2.40 & 2.86 & 2.05 & 0.56 & 0.97\end{array}$

$\begin{array}{lllllllllll}90 \mathrm{Q} 3 & 3.77 & 3.51 & 0.49 & 0.95 & 2.27 & 2.25 & 2.40 & 1.99 & 0.60 & 0.99\end{array}$

$\begin{array}{lllllllllll}90 Q 4 & 2.90 & 4.77 & 0.50 & 1 Q & 2.03 & 3.57 & 1.98 & 3.16 & 0.61 & 0.96\end{array}$

$\begin{array}{lllllllllll}91 \mathrm{Q} 1 & 3.74 & 7.95 & 0.50 & 1.03 & 2.14 & 4.05 & 2.05 & 3.59 & 0.57 & 0.94\end{array}$
\end{abstract}




\section{References}

Atkeson, Andrew and Patrick J. Kehoe, "Measuring Organization Capital," NBER working paper no. 8722 .

Barlevy, Gadi (1998) "Sectoral Reallocation and Aggregate Unemployment: Further Evidence from the PSID”, mimeo, Northwestern University.

Baxter, Marianne and Robert G. King (1999) "Measuring Business Cycles: Approximate BandPass filters for Economic Time Series," The Review of Economics and Statistics, 81(4), pp. 575-93.

Burns, Arthur, and Wesley C. Mitchell, Measuring Business Cycles, New York: National Bureau of Economic Research, 1946.

Caballero Ricardo and Mohamad Hammour (1994) “The Cleansing Effect of Recessions," American Economic Review, 84(5), 1350-1368.

Caballero, Ricardo and Mohamad Hammour (1996) "On the Timing and Efficiency of Creative Destruction," Quarterly Journal of Economics, 111(3), 805-852.

Caballero, Ricardo and Mohamad Hammour (1998) "Improper Churn: Social Costs and Macroeconomic Consequences,” NBER Working Paper No. 6717.

Campbell, Jeffrey and Jonas Fisher (2000) "Aggregate Employment Fluctuations with Microeconomic Asymmetries," American Economic Review, 90(5), pp. 1323-1345.

Clark, Kim and Lawrence Summers (1979) "Labor Market Dynamics and Unemployment: Reconsideration," Brookings Papers on Economic Activity, 1, pp. 13-60.

Cole, Harold L. and Richard Rogerson (1999) "Can the Mortensen-Pissarides Matching Model Match the Business-Cycle Facts?” International Economic Review, 40(4), November, pp. 933-959.

Darby, Michael R., Haltiwanger, John and Mark Plant (1985) "Unemployment Rate Dynamics and Persistent Unemployment under Rational Expectations," American Economic Review, 75(4), pp. 614-637.

Davis, Steven, John Haltiwanger, and Scott Schuh (1996) Job Creation and Destruction, Cambridge, MA: MIT Press. 
Feldstein, Martin S.(1975) "The Importance of Temporary Layoffs: An Empirical Analysis," Brookings Papers on Economic-Activity, 3, pp. 725-44.

Figura, Andrew (2001) "Is Reallocation Related to the Cycle? A Look at Permanent and Temporary Job Flows," mimeo, Board of Governors of the Federal Reserve System.

Foote, Christopher L. (1998) "Trend Employment Growth and the Bunching of Job Creation and Destruction," Quarterly Journal of Economics, 113(3), pp. 809-34.

Lilien, David (1980) "The Cyclical Pattern of Temporary Layoffs in United States Manufacturing, The Review of Economics and Statistics, 52(1), pp. 24-31.

Loungani, Prakesh and Richard Rogerson (1989) "Cyclical Fluctuations and the Sectoral Reallocation of Labor: Evidence from the PSID,” Journal of Monetary Economics 23(2), pp. 259-273.

Mortensen, Dale, and Christopher A. Pissarides (1994) "Job Creation and Job Destruction in the Theory of Unemployment," Review of Economic Studies, 61, pp. 397-415.

Murphy, Kevin M. and Robert Topel (1987) "The Evolution of Unemployment in the United States: 1968-1985," NBER Macroeconomics Annual, Ed. Stanley Fischer, pp. 11-58.

Priestly, M.B. (1981) Spectral Analysis and Time Series, Boston: Harcourt Brace \& Co.

Prescott, Edward C. And Michael Visscher (1980) "Organization Capital," Journal of Political Economy, 88(3), pp. 446-461.

Ramey, Gary and Joel Watson (1997) "Contractual Fragility, Job Destruction and Business Cycles," Quarterly Journal of Economics, 112 (3), pp. 873-911.

Ramey, Valerie A. and Matthew D. Shapiro (1998) "Displaced Capital," NBER working paper no. 6775 .

Sichel, Dan (1993) "Inventories and the Three Phases of the Business Cycle," Journal of Business and Economic Statistics, 12 (3), pp. 269-77.

Starr-McCluer, Martha (1993) "Cyclical Fluctuations and Sectoral Reallocation: A Reexamination," Journal of Monetary Economics, 31, pp. 417-25. 
Table 1. Comparison of Job Flows from the ASM and Overlapping 7 Year Panels

Panel A. Job Flows from the Complete ASM

\begin{tabular}{lcccc} 
& Job Creation & Job Destruction & NET & SUM \\
\hline Mean & 5.04 & 5.57 & -0.53 & 10.62 \\
Standard Deviation & 0.88 & 1.67 & 2.01 & 1.75 \\
Maximum & 7.32 & 11.42 & 2.55 & 14.67 \\
Minimum & 3.25 & 3.32 & -8.17 & 6.91
\end{tabular}

Panel B. Job Flows from the Overlapping 7 Year Panels

\begin{tabular}{lcccc} 
& Job Creation & Job Destruction & NET & SUM \\
\hline Mean & 4.05 & 4.48 & -0.43 & 8.53 \\
Standard Deviation & 0.92 & 1.53 & 1.98 & 1.57 \\
Maximum & 6.91 & 10.80 & 2.73 & 12.93 \\
Minimum & 2.13 & 2.24 & -8.67 & 4.90 \\
$\begin{array}{l}\text { Correlation with } \\
\text { Complete ASM }\end{array}$ & 0.83 & 0.93 & 0.96 & 0.82 \\
Flow & & & &
\end{tabular}


Table 2. Component Job Flows

Panel A. Long-term Job Flows

\begin{tabular}{lcccc} 
& Job Creation & Job Destruction & NET & SUM \\
\hline Mean & 0.60 & 0.94 & -0.35 & 1.54 \\
Standard Deviation & 0.10 & 0.23 & 0.32 & 0.17 \\
Maximum & 0.79 & 1.40 & 0.24 & 1.96 \\
Minimum & 0.39 & 0.55 & -1.02 & 1.32
\end{tabular}

Panel B. Cyclical Job Flows- 1-8 Years

\begin{tabular}{lcccc} 
& Job Creation & Job Destruction & NET & SUM \\
\hline Mean & 3.00 & 3.05 & -0.05 & 6.05 \\
Standard Deviation & 0.75 & 1.02 & 1.56 & 0.90 \\
Maximum & 4.88 & 7.57 & 2.62 & 9.05 \\
Minimum & 1.48 & 1.85 & -6.09 & 4.48
\end{tabular}

Panel C. High Frequency Cyclical Job Flows- Periods from 1-4 Years

\begin{tabular}{lcccc} 
& Job Creation & Job Destruction & NET & SUM \\
\hline Mean & 2.80 & 2.86 & -0.06 & 5.66 \\
Standard Deviation & 0.71 & 0.82 & 1.31 & 0.79 \\
Maximum & 4.98 & 6.38 & 2.87 & 7.96 \\
Minimum & 1.58 & 1.82 & -4.80 & 4.30
\end{tabular}

Panel D. Medium Frequency Cyclical Job Flows- Periods from 5-8 Years

\begin{tabular}{lcccc} 
& Job Creation & Job Destruction & NET & SUM \\
\hline Mean & 0.88 & 0.87 & 0.01 & 1.75 \\
Standard Deviation & 0.33 & 0.31 & 0.62 & 0.18 \\
Maximum & 1.70 & 1.67 & 1.30 & 2.10 \\
Minimum & 0.37 & 0.40 & -1.30 & 1.44
\end{tabular}


Table 2 Continued.

Panel E. Total Job Flows

\begin{tabular}{lcccc} 
& Job Creation & Job Destruction & NET & SUM \\
\hline Mean & 4.05 & 4.48 & -0.43 & 8.53 \\
Standard Deviation & 0.92 & 1.53 & 1.98 & 1.57 \\
Maximum & 6.91 & 10.80 & 2.73 & 12.93 \\
Minimum & 2.13 & 2.24 & -8.67 & 4.90
\end{tabular}


Table 3. Relationship Between Trend Growth and the Variance Ratio for Different Job Flow Components

\begin{tabular}{lcc} 
& $\beta$ & $\mathrm{R}^{2}$ \\
\hline Long-term Job Flows & 0.65 & 0.99 \\
Cyclical Job Flows- Periods from 1-8 Years & -0.01 & 0.03 \\
Cyclical Job Flows- Periods from 1-4 Years & 0.00 & 0.01 \\
Cyclical Job Flows- Periods from 5-8 Years & -0.06 & 0.63
\end{tabular}


Table 4. Variance Ratios by Deciles of Plant Characteristics

Panel A. Long-term Job Flows

\begin{tabular}{|c|c|c|c|c|c|c|}
\hline \multirow[b]{2}{*}{ Decile } & \multicolumn{3}{|c|}{ Size } & \multicolumn{3}{|c|}{ Energy Intensity } \\
\hline & Creation & Destruction & Ratio & Creation & Destruction & Ratio \\
\hline 1 & 0.20 & 0.27 & 0.74 & 0.13 & 0.16 & 0.82 \\
\hline 2 & 0.18 & 0.23 & 0.79 & 0.12 & 0.18 & 0.68 \\
\hline 3 & 0.17 & 0.24 & 0.72 & 0.14 & 0.24 & 0.57 \\
\hline 4 & 0.15 & 0.26 & 0.58 & 0.11 & 0.24 & 0.47 \\
\hline 5 & 0.16 & 0.26 & 0.62 & 0.13 & 0.24 & 0.56 \\
\hline 6 & 0.13 & 0.24 & 0.56 & 0.09 & 0.21 & 0.44 \\
\hline 7 & 0.13 & 0.21 & 0.61 & 0.11 & 0.24 & 0.44 \\
\hline 8 & 0.10 & 0.19 & 0.54 & 0.11 & 0.23 & 0.46 \\
\hline 9 & 0.10 & 0.20 & 0.51 & 0.08 & 0.27 & 0.30 \\
\hline \multirow[t]{2}{*}{10} & 0.09 & 0.27 & 0.36 & 0.10 & 0.43 & 0.23 \\
\hline & \multicolumn{3}{|c|}{ Wages } & \multicolumn{3}{|c|}{ Shipments/worker } \\
\hline Decile & Creation & Destruction & Ratio & Creation & Destruction & Ratio \\
\hline 1 & 0.09 & 0.13 & 0.71 & 0.07 & 0.12 & 0.59 \\
\hline 2 & 0.12 & 0.15 & 0.81 & 0.11 & 0.20 & 0.54 \\
\hline 3 & 0.12 & 0.20 & 0.62 & 0.14 & 0.29 & 0.47 \\
\hline 4 & 0.15 & 0.21 & 0.71 & 0.14 & 0.35 & 0.40 \\
\hline 5 & 0.15 & 0.23 & 0.65 & 0.12 & 0.33 & 0.36 \\
\hline 6 & 0.13 & 0.28 & 0.47 & 0.12 & 0.32 & 0.35 \\
\hline 7 & 0.11 & 0.24 & 0.46 & 0.13 & 0.31 & 0.41 \\
\hline 8 & 0.10 & 0.30 & 0.33 & 0.12 & 0.25 & 0.47 \\
\hline 9 & 0.10 & 0.26 & 0.37 & 0.14 & 0.21 & 0.68 \\
\hline 10 & 0.14 & 0.35 & 0.39 & 0.12 & 0.18 & 0.66 \\
\hline
\end{tabular}


Table 4 Continued

Panel B. Cyclical Job Flows- Periods from 1-8 Years

\begin{tabular}{cccc|ccc} 
& & \multicolumn{3}{c}{ Size } & \multicolumn{3}{c}{ Energy Intensity } \\
Decile & Creation & Destruction & Ratio & Creation & Destruction & Ratio \\
\hline 1 & 0.82 & 1.06 & 0.78 & 0.92 & 1.15 & 0.80 \\
2 & 0.78 & 0.97 & 0.80 & 0.78 & 1.05 & 0.74 \\
3 & 0.73 & 1.07 & 0.68 & 0.71 & 1.01 & 0.70 \\
4 & 0.80 & 1.09 & 0.74 & 0.74 & 0.96 & 0.78 \\
5 & 0.75 & 1.10 & 0.68 & 0.77 & 1.14 & 0.67 \\
6 & 0.77 & 1.09 & 0.71 & 0.78 & 0.98 & 0.80 \\
7 & 0.78 & 1.12 & 0.70 & 0.84 & 1.12 & 0.75 \\
8 & 0.80 & 1.08 & 0.74 & 0.85 & 1.12 & 0.75 \\
9 & 0.75 & 1.08 & 0.70 & 0.78 & 1.02 & 0.76 \\
10 & 0.83 & 1.05 & 0.79 & 0.91 & 1.12 & 0.81 \\
\hline
\end{tabular}

\begin{tabular}{cccc|ccc}
\hline & \multicolumn{3}{c}{ Wages } & \multicolumn{3}{c}{ Shipments/worker } \\
Decile & Creation & Destruction & Ratio & Creation & Destruction & Ratio \\
\hline 1 & 0.91 & 1.20 & 0.76 & 0.85 & 1.01 & 0.84 \\
2 & 0.93 & 1.21 & 0.77 & 0.96 & 1.16 & 0.82 \\
3 & 0.83 & 1.13 & 0.74 & 0.96 & 1.26 & 0.76 \\
4 & 0.90 & 1.19 & 0.75 & 0.98 & 1.27 & 0.78 \\
5 & 0.86 & 1.25 & 0.69 & 1.01 & 1.28 & 0.79 \\
6 & 0.82 & 1.13 & 0.72 & 0.97 & 1.26 & 0.77 \\
7 & 0.72 & 1.11 & 0.65 & 0.86 & 1.11 & 0.77 \\
8 & 0.66 & 0.95 & 0.69 & 0.66 & 0.93 & 0.71 \\
9 & 0.60 & 0.84 & 0.72 & 0.54 & 0.87 & 0.62 \\
10 & 1.21 & 1.36 & 0.89 & 0.36 & 0.60 & 0.60 \\
\hline
\end{tabular}


Table 4 Continued

Panel C. Short-term Job Flows, 1-4 Years

\begin{tabular}{|c|c|c|c|c|c|c|}
\hline \multirow[b]{2}{*}{ Decile } & \multicolumn{3}{|c|}{ Size } & \multicolumn{3}{|c|}{ Energy Intensity } \\
\hline & Creation & Destruction & Ratio & Creation & Destruction & Ratio \\
\hline 1 & 0.68 & 0.83 & 0.82 & 0.81 & 0.95 & 0.85 \\
\hline 2 & 0.65 & 0.76 & 0.85 & 0.75 & 0.84 & 0.89 \\
\hline 3 & 0.67 & 0.86 & 0.79 & 0.67 & 0.80 & 0.84 \\
\hline 4 & 0.73 & 0.87 & 0.85 & 0.68 & 0.75 & 0.90 \\
\hline 5 & 0.69 & 0.89 & 0.77 & 0.75 & 0.92 & 0.81 \\
\hline 6 & 0.70 & 0.86 & 0.82 & 0.73 & 0.78 & 0.93 \\
\hline 7 & 0.72 & 0.90 & 0.80 & 0.79 & 0.91 & 0.87 \\
\hline 8 & 0.74 & 0.88 & 0.84 & 0.80 & 0.91 & 0.88 \\
\hline 9 & 0.72 & 0,87 & 0.82 & 0.73 & 0.84 & 0.87 \\
\hline \multirow[t]{2}{*}{10} & 0.80 & 0.84 & 0.96 & 0.89 & 0.94 & 0.94 \\
\hline & \multicolumn{3}{|c|}{ Wages } & \multicolumn{3}{|c|}{ Shipments/worker } \\
\hline Decile & Creation & Destruction & Ratio & Creation & Destruction & Ratio \\
\hline 1 & 0.82 & 1.00 & 0.82 & 0.77 & 0.83 & 0.92 \\
\hline 2 & 0.88 & 1.01 & 0.88 & 0.86 & 0.96 & 0.90 \\
\hline 3 & 0.78 & 0.91 & 0.86 & 0.92 & 1.02 & 0.90 \\
\hline 4 & 0.85 & 0.96 & 0.88 & 0.94 & 1.05 & 0.89 \\
\hline 5 & 0.82 & 1.00 & 0.82 & 0.95 & 1.05 & 0.90 \\
\hline 6 & 0.77 & 0.90 & 0.85 & 0.93 & 1.00 & 0.93 \\
\hline 7 & 0.67 & 0.87 & 0.77 & 0.83 & 0.89 & 0.94 \\
\hline 8 & 0.58 & 0.74 & 0.78 & 0.63 & 0.74 & 0.86 \\
\hline 9 & 0.52 & 0.66 & 0.79 & 0.50 & 0.68 & 0.74 \\
\hline 10 & 1.22 & 1.14 & 1.07 & 0.31 & 0.48 & 0.65 \\
\hline
\end{tabular}


Table 4 Continued

Panel D. Short-term Job Flows, 5-8 Years

\begin{tabular}{|c|c|c|c|c|c|c|}
\hline \multirow[b]{2}{*}{ Decile } & \multicolumn{3}{|c|}{ Size } & \multicolumn{3}{|c|}{ Energy Intensity } \\
\hline & Creation & Destruction & Ratio & Creation & Destruction & Ratio \\
\hline 1 & 0.31 & 0.35 & 0.88 & 0.39 & 0.34 & 1.14 \\
\hline 2 & 0.33 & 0.35 & 0.94 & 0.34 & 0.32 & 1.07 \\
\hline 3 & 0.34 & 0.33 & 1.02 & 0.31 & 0.33 & 0.93 \\
\hline 4 & 0.34 & 0.35 & 0.99 & 0.34 & 0.31 & 1.08 \\
\hline 5 & 0.32 & 0.34 & 0.96 & 0.33 & 0.34 & 1.00 \\
\hline 6 & 0.34 & 0.33 & 1.05 & 0.34 & 0.31 & 1.10 \\
\hline 7 & 0.34 & 0.33 & 1.04 & 0.36 & 0.35 & 1.04 \\
\hline 8 & 0.31 & 0.31 & 1.01 & 0.37 & 0.34 & 1.09 \\
\hline 9 & 0.32 & 0.32 & 0.99 & 0.30 & 0.30 & 0.99 \\
\hline \multirow[t]{2}{*}{10} & 0.34 & 0.32 & 1.07 & 0.33 & 0.32 & 1.03 \\
\hline & \multicolumn{3}{|c|}{ Wages } & \multicolumn{3}{|c|}{ Shipments/worker } \\
\hline Decile & Creation & Destruction & Ratio & Creation & Destruction & Ratio \\
\hline 1 & 0.32 & 0.30 & 1.07 & 0.29 & 0.28 & 1.06 \\
\hline 2 & 0.33 & 0.34 & 0.99 & 0.37 & 0.35 & 1.06 \\
\hline 3 & 0.34 & 0.34 & 1.00 & 0.39 & 0.39 & 1.00 \\
\hline 4 & 0.37 & 0.36 & 1.02 & 0.42 & 0.41 & 1.03 \\
\hline 5 & 0.40 & 0.40 & 0.99 & 0.42 & 0.38 & 1.09 \\
\hline 6 & 0.36 & 0.39 & 0.93 & 0.43 & 0.37 & 1.16 \\
\hline 7 & 0.33 & 0.35 & 0.96 & 0.38 & 0.34 & 1.13 \\
\hline 8 & 0.33 & 0.33 & 1.00 & 0.30 & 0.29 & 1.02 \\
\hline 9 & 0.29 & 0.30 & 0.98 & 0.24 & 0.28 & 0.87 \\
\hline 10 & 0.40 & 0.32 & 1.25 & 0.16 & 0.16 & 1.00 \\
\hline
\end{tabular}


Table 5. Decoupling by Decile of Plant Characteristics

Panel A. Long-term Job Flows

Contemporaneous Correlation

\begin{tabular}{ccccc} 
Decile & Size & Energy Intensity & Wages & Shipments/worker \\
\hline 1 & -0.82 & -0.74 & -0.52 & -0.55 \\
2 & -0.77 & -0.75 & -0.83 & -0.67 \\
3 & -0.81 & -0.83 & -0.77 & -0.84 \\
4 & -0.74 & -0.81 & -0.81 & -0.76 \\
5 & -0.83 & -0.74 & -0.74 & -0.69 \\
6 & -0.84 & -0.73 & -0.87 & -0.76 \\
7 & -0.81 & -0.69 & -0.82 & -0.78 \\
8 & -0.76 & -0.79 & -0.73 & -0.64 \\
9 & -0.73 & -0.78 & -0.78 & -0.81 \\
10 & -0.69 & -0.89 & -0.47 & -0.93
\end{tabular}

Panel B. Cyclical Job Flows- 1-8 Years

Contemporaneous Correlation

\begin{tabular}{ccccc} 
Decile & Size & Energy Intensity & Wages & Shipments/worker \\
\hline 1 & 0.01 & -0.44 & -0.52 & -0.51 \\
2 & -0.23 & -0.50 & -0.52 & -0.57 \\
3 & -0.30 & -0.51 & -0.61 & -0.45 \\
4 & -0.30 & -0.52 & -0.46 & -0.45 \\
5 & -0.46 & -0.51 & -0.51 & -0.40 \\
6 & -0.42 & -0.53 & -0.47 & -0.62 \\
7 & -0.57 & -0.43 & -0.48 & -0.58 \\
8 & -0.53 & -0.63 & -0.53 & -0.49 \\
9 & -0.50 & -0.51 & -0.50 & -0.45 \\
10 & -0.55 & -0.42 & -0.49 & -0.17
\end{tabular}


Table 5. Continued

Panel C. High Frequency Cyclical Job Flows- 1-4 Years

\section{Contemporaneous Correlation}

\begin{tabular}{ccccc} 
Decile & Size & Energy Intensity & Wages & Shipments/worker \\
\hline 1 & 0.06 & -0.38 & -0.53 & -0.50 \\
2 & -0.18 & -0.46 & -0.49 & -0.52 \\
3 & -0.27 & -0.42 & -0.57 & -0.37 \\
4 & -0.23 & -0.46 & -0.40 & -0.40 \\
5 & -0.42 & -0.45 & -0.44 & -0.32 \\
6 & -0.36 & -0.47 & -0.42 & -0.55 \\
7 & -0.54 & -0.36 & -0.39 & -0.54 \\
8 & -0.48 & -0.59 & -0.46 & -0.43 \\
9 & -0.45 & -0.48 & -0.45 & -0.42 \\
10 & -0.49 & -0.38 & -0.45 & -0.09
\end{tabular}

Panel D. Medium Frequency Cyclical Job Flows, 5-8 Years

Contemporaneous Correlation

\begin{tabular}{ccccc} 
Decile & Size & Energy Intensity & Wages & Shipments/worker \\
\hline 1 & -0.78 & -0.75 & -0.85 & -0.85 \\
2 & -0.87 & -0.84 & -0.83 & -0.87 \\
3 & -0.84 & -0.84 & -0.88 & -0.78 \\
4 & -0.78 & -0.85 & -0.81 & -0.77 \\
5 & -0.82 & -0.78 & -0.83 & -0.76 \\
6 & -0.84 & -0.83 & -0.83 & -0.87 \\
7 & -0.86 & -0.79 & -0.84 & -0.83 \\
8 & -0.85 & -0.86 & -0.86 & -0.82 \\
9 & -0.84 & -0.86 & -0.86 & -0.84 \\
10 & -0.83 & -0.73 & -0.73 & -0.84
\end{tabular}


Figure 1. Short-term and long-term Job Flows

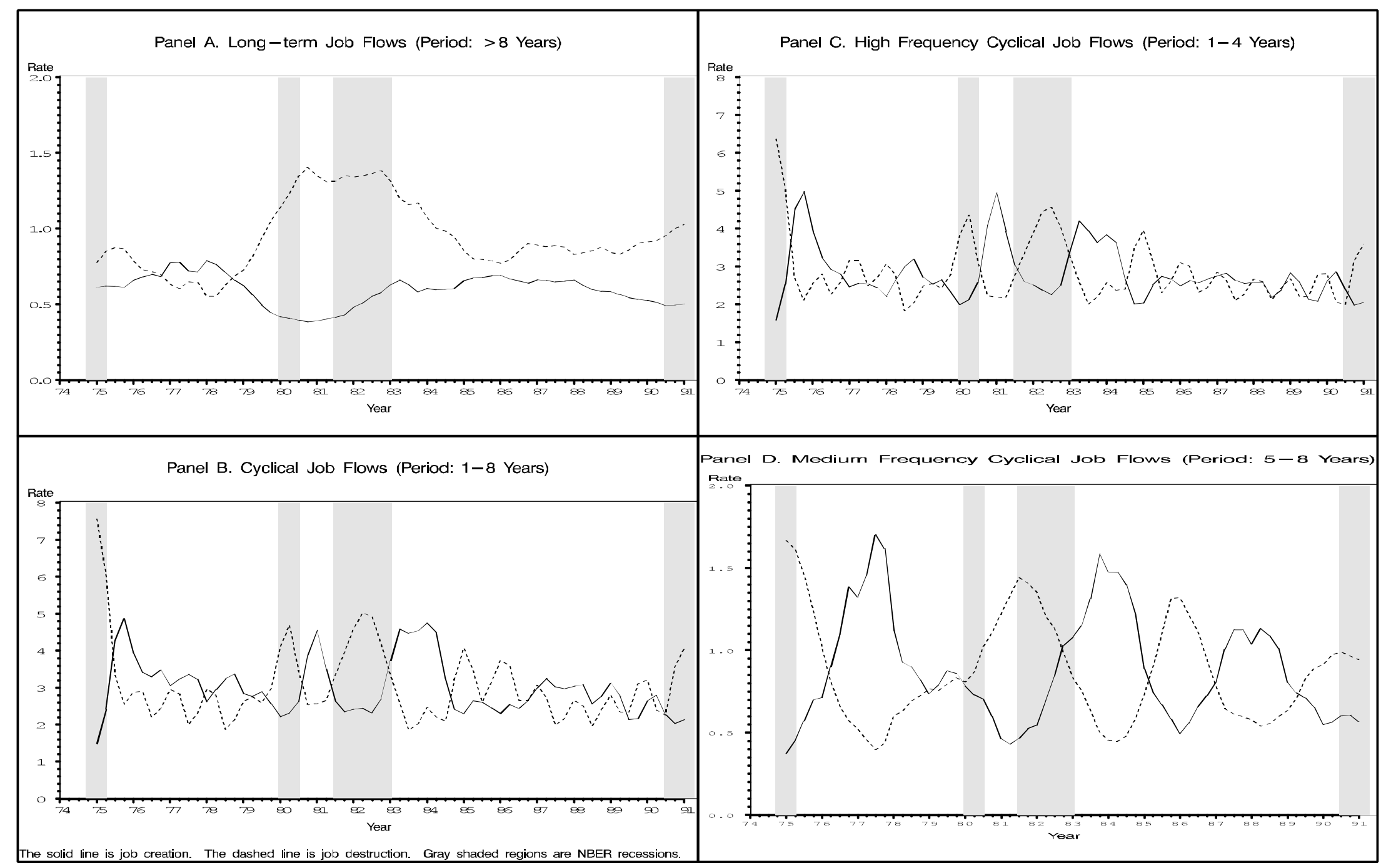


Figure 2. Total Job flows for Overlapping 7 Year Panels

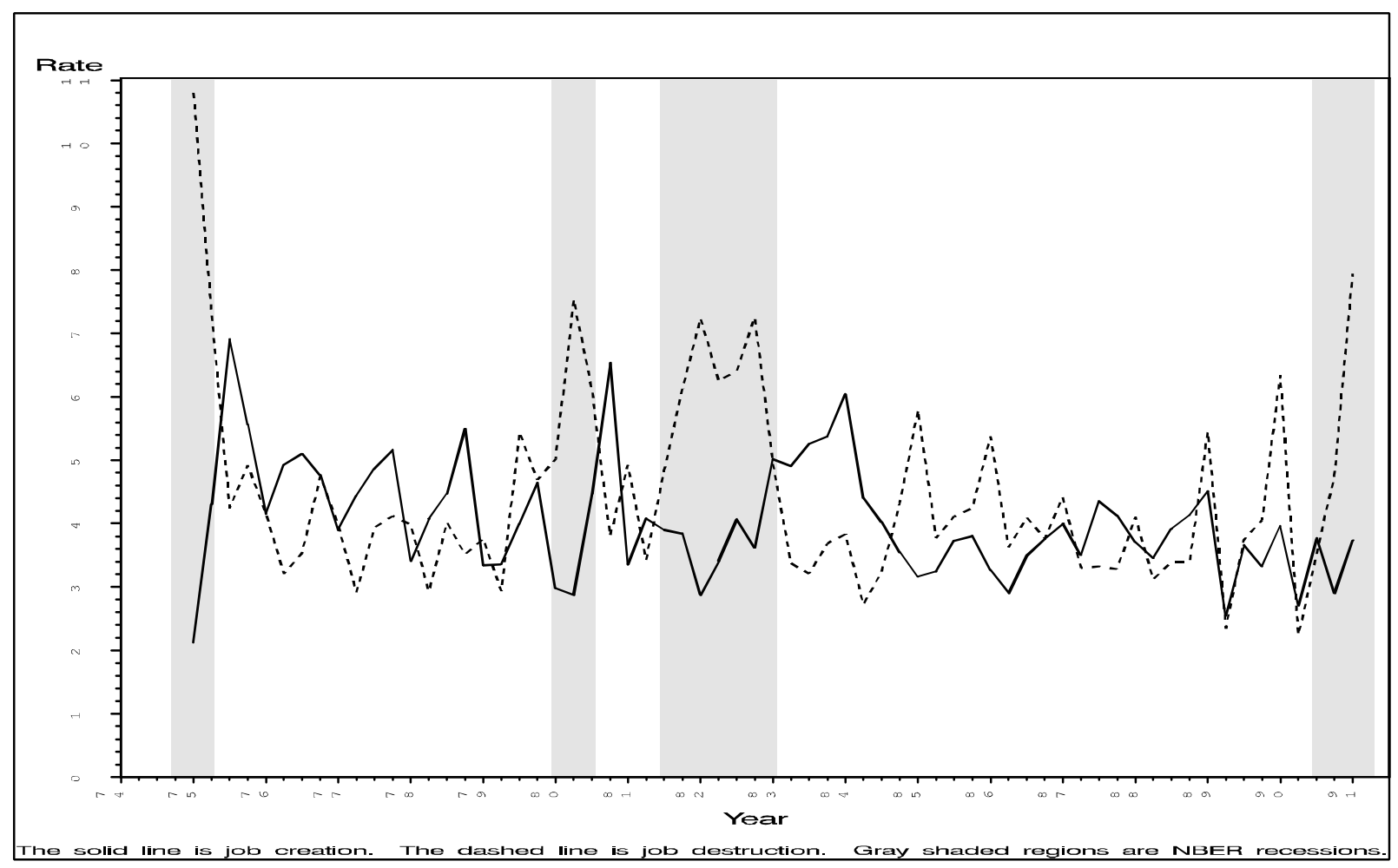


Figure 3. Relationship Between Trend Growth and the Standard Deviation Ratio

4 Digit Industries, $1972-1986$

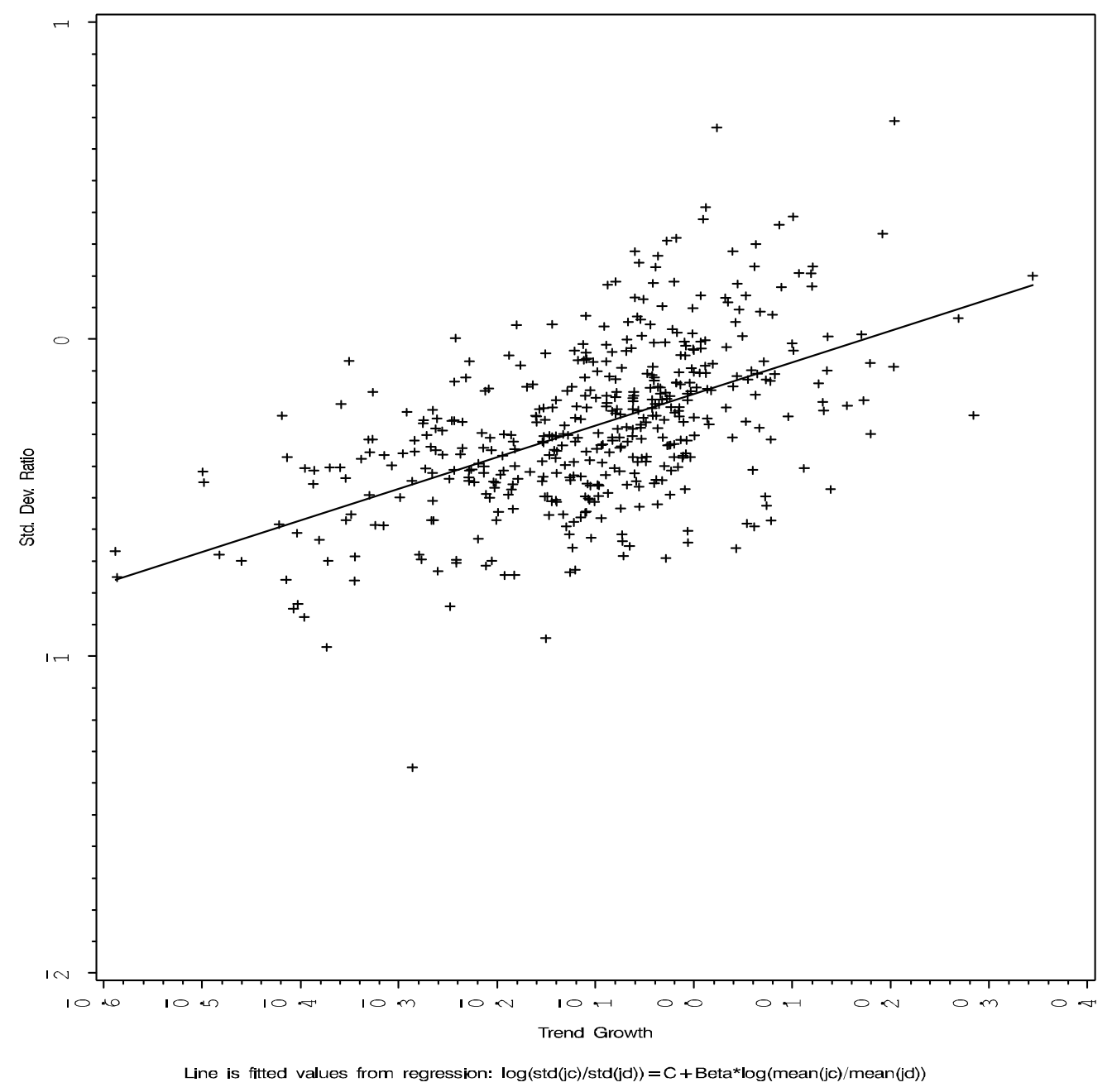

$-40-$ 
Figure 4. Dynamic Correlations of Job Flows

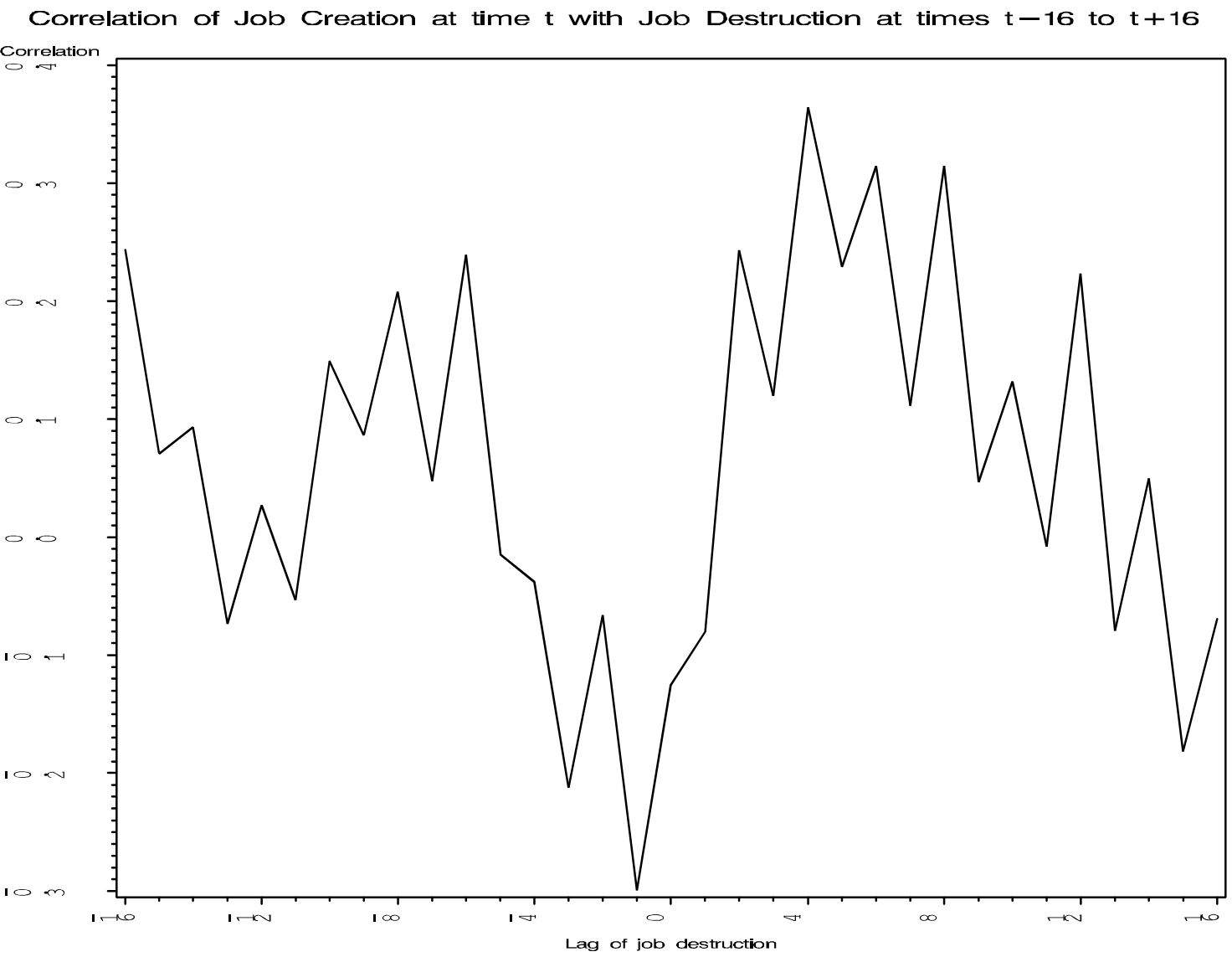


Figure 5. Relationship Between Trend Growth and the Standard Deviation Ratio for Component Job Flows

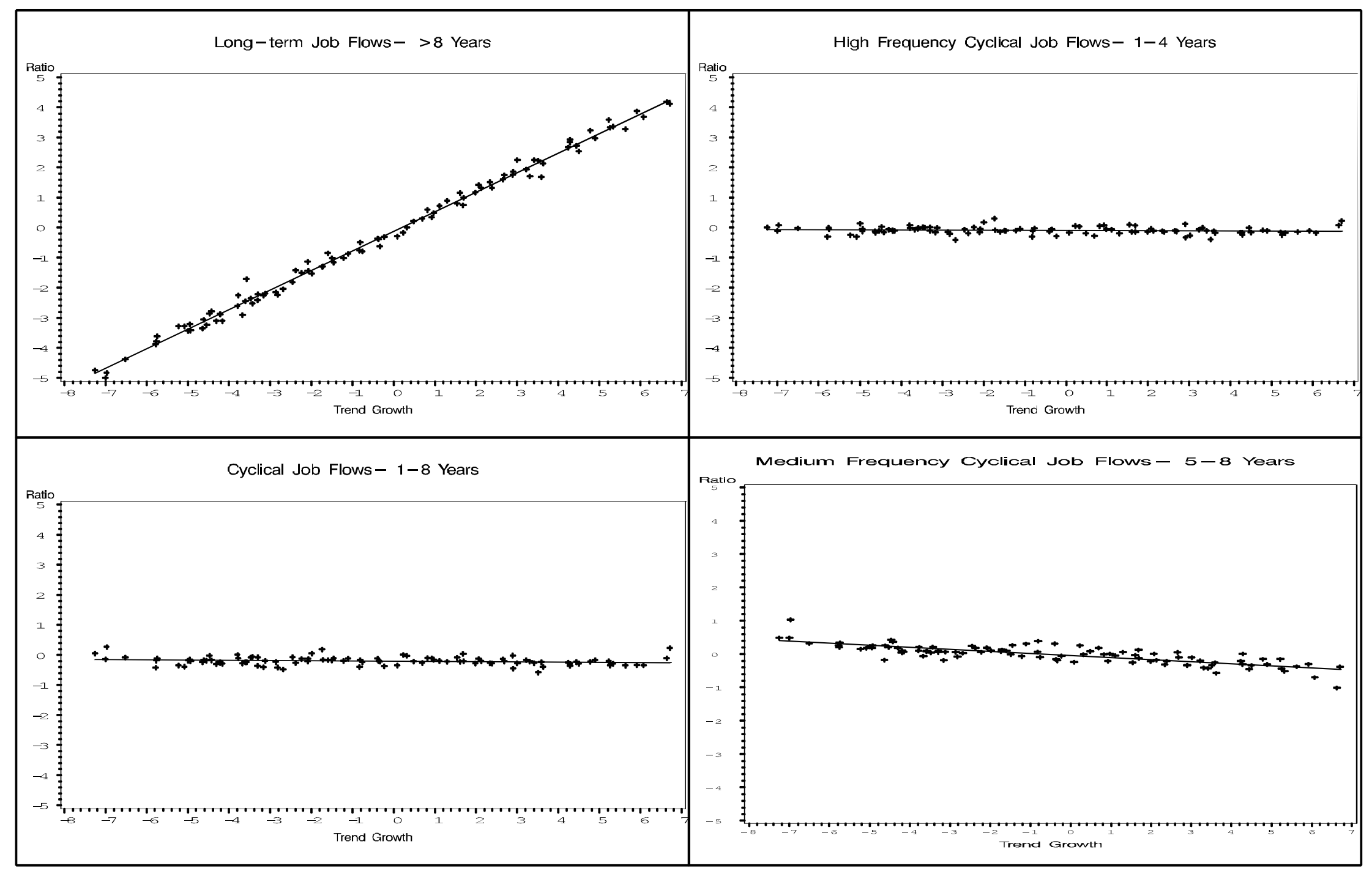


Figure 6. Dynamic Correlations of Component Job Flows

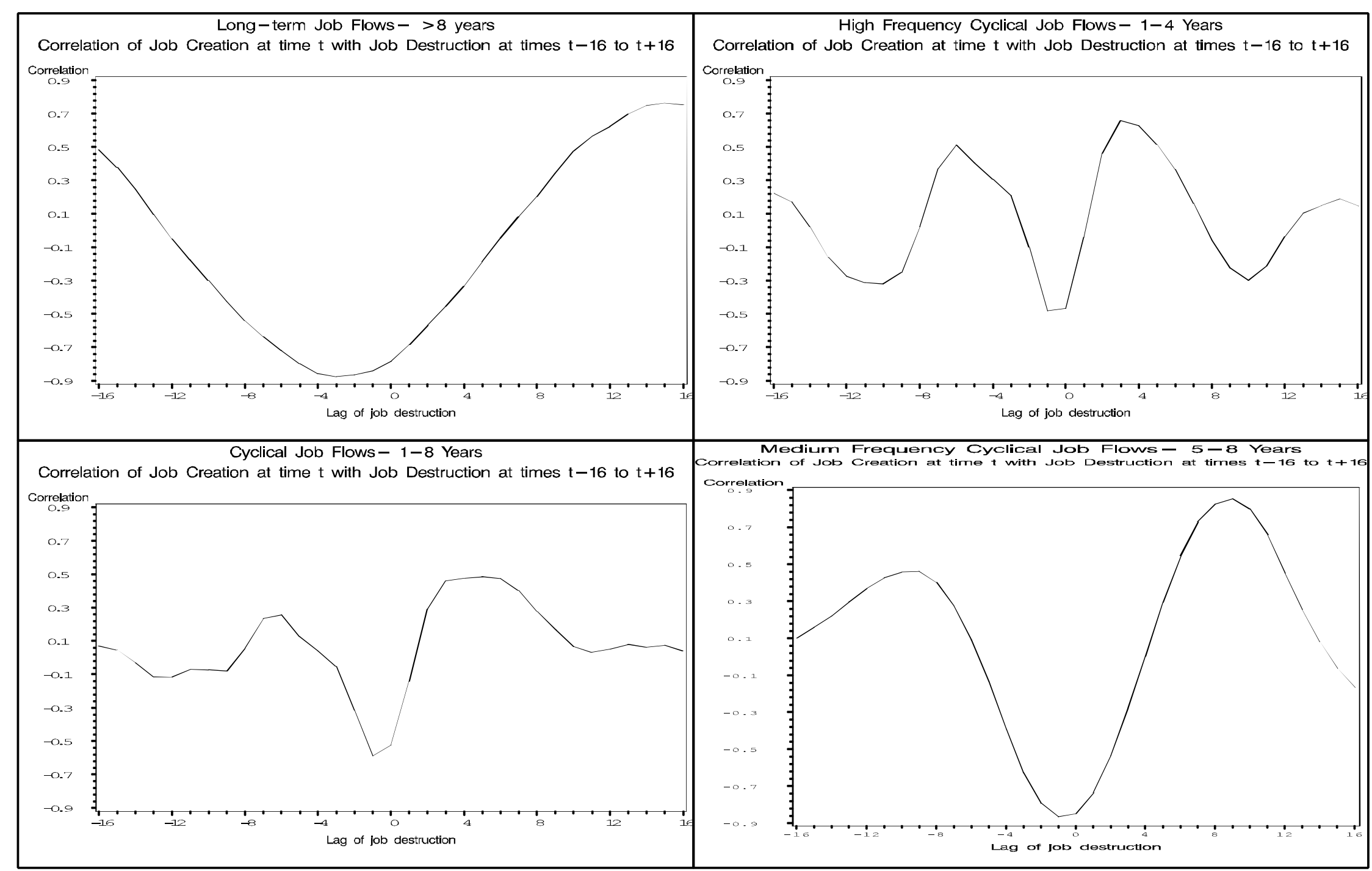


